\title{
A Review of the Role of Bioenergy Modelling in Renewable Energy Research \& Policy Development
}

\section{Contact Details}

\begin{tabular}{|c|c|c|c|}
\hline $\begin{array}{c}\text { Dr. } \\
\text { Andrew } \\
\text { Welfle }\end{array}$ & $\begin{array}{c}\text { Supergen } \\
\text { Bioenergy Hub, } \\
\text { Tyndall Centre for } \\
\text { Climate Change } \\
\text { Research }\end{array}$ & $\begin{array}{c}\text { Department of Mechanical, } \\
\text { Aerospace \& Civil } \\
\text { Engineering, Pariser } \\
\text { Building, The University of } \\
\text { Manchester, Sackville } \\
\text { Street, Manchester, M13 } \\
\text { 9PL, UK }\end{array}$ & andrew.welfle@manchester.ac.uk \\
\hline $\begin{array}{c}\text { Prof. } \\
\text { Patricia } \\
\text { Thornley }\end{array}$ & $\begin{array}{c}\text { Supergen } \\
\text { Bioenergy Hub, } \\
\text { Energy and } \\
\text { Bioproducts } \\
\text { Research Institute }\end{array}$ & $\begin{array}{l}\text { School of Engineering \& } \\
\text { Applied Science, Aston } \\
\text { University, Aston Triangle, } \\
\text { Birmingham, B4 7ET, UK }\end{array}$ & p.thornley@aston.ac.uk \\
\hline $\begin{array}{c}\text { Dr. } \\
\text { Mirjam } \\
\text { Röder }\end{array}$ & $\begin{array}{c}\text { Supergen } \\
\text { Bioenergy Hub, } \\
\text { Energy and } \\
\text { Bioproducts } \\
\text { Research Institute }\end{array}$ & $\begin{array}{l}\text { School of Engineering \& } \\
\text { Applied Science, Aston } \\
\text { University, Aston Triangle, } \\
\text { Birmingham, B4 7ET, UK }\end{array}$ & m.roeder@aston.ac.uk \\
\hline
\end{tabular}

C2020. This manuscript version is made available under the CC-BY-NC-ND 4.0

license http://creativecommons.org/licenses/by-nc-nd/4.0/

\begin{abstract}
Transition towards renewable low carbon energy is a fundamental element of climate change mitigation, energy from biomass technologies are targeted within many country's decarbonisation strategies. Decision makers globally face many challenges developing strategies to drive this transition; models are increasingly used to road-test policy interventions before their implemented. A Bioenergy Literature Database was developed of 124,285 papers published 2000-2018. These document an exponential rise in research focusing on biomass and bioenergy. On average $35.4 \%$ of papers apply modelling analyses, $99.5 \%$ of these use bespoke models rather than high profile Integrated Assessment Models (IAMs) or Energy System Models - although it is these high profile models that are widely used in policy development. A review of the role of bioenergy within energy models is undertaken with a key objective of critiquing their performances in analysing bioenergy research questions. IAMs are found to be widely applied to investigate the impact of bioenergy within wider energy and environmental systems, e.g. for reducing emissions. Energy System Models focus on bioenergy processes, technologies and feedstocks, although don't capture wider environmental, economic and social themes. Specialist Bioenergy Models offer methods for bespoke analyses of all bioenergy issues, their narrow system boundaries generate targeted outputs but wider effects such as land-use change may not be captured. Caution is required when interpreting modelling outputs, particularly when used to inform policy. It's not feasible to develop all-encompassing bioenergy models covering all nuances between systems, but there is strong argument for using multiple models in parallel to build robust overall conclusions.
\end{abstract}




\section{Keywords}

Bioenergy, Models, Energy System Models, Integrated Assessment Models, Policy Development, Review

\section{Highlights}

- Policy is developed disproportionality using high profile Energy Models.

- $99.5 \%$ bioenergy modelling research uses bespoke models.

- Bioenergy modelling outputs limited by design \& assumption of the model.

- Different modelling approaches do not/ cannot cover all bioenergy research topics.

- Strong argument for using multiple models for more robust overall conclusions. 


\section{Introduction}

The transition of energy systems towards renewable low carbon energy technologies is a key measure in climate change mitigation. The development of energy strategies for an increasing number of governments is now framed by their commitments for achieving international targets such as those laid out by the Paris Agreement where the principal target is to hold global average temperature well below $2{ }^{\circ} \mathrm{C}$ above pre-industrial levels and to pursue efforts to limit the temperature increase to $1.5^{\circ} \mathrm{C}$ above pre-industrial levels [1]. As a consequence many countries have national targets to become carbon-neutral by 2050 (UK, France, Spain, New Zealand), by 2045 (Sweden) by 2030 (Norway) with many other countries considering net zero carbon options [2]. The key current questions for the energy sector relate to the choice of the mix of low carbon technologies that will be deployed, how these may provide cost effective options that deliver the required levels and forms of energy, and the speed that the energy sector can decarbonise whilst supporting the transition to a low carbon society. This is a complex issues due to the intricacies of the energy sector, given the diversity in the forms of energy required (heat, power, fuels etc), the energy demands (buildings, industry etc), and the multiple wider activities that the energy sector drives (transportations, agriculture etc).

The Intergovernmental Panel on Climate Change (IPCC) report that $35 \%$ of global greenhouse gas emissions are attributed to the energy sector [3]. Reducing energy demands and increasing efficiency is the most cost effective strategy for reducing energy sector emissions [4]; but with renewable low carbon energy technologies progressively dropping in price and crucially becoming closer in cost parity to that of established fossil fuel generation, renewables provide an increasingly attractive mechanism for decarbonisation [5].

\subsection{Role of Modelling in Developing Energy Strategies}

Due to variability in geography, resource availability, infrastructural development, end-user demand, financial constraints and sometimes very different historic approaches to energy; individual country's policy makers face unique sets of challenges in developing policy frameworks and strategies to drive the transition toward energy decarbonisation. To help develop strategies and evaluate the potential influence and impacts of different policy options, energy models are used by decision makers to roadtest plans before they are implemented [6].

Models can provide the essential quantitative insights into alternative designs for energy scenarios, roadmaps or systems and thus decrease the pervasive uncertainties of different options - leading to better energy decisions [7]. With the rise in types of energy technologies available and the increased complexity and performance demands for energy systems there has been an equivalent rise in the number, types and approaches of energy models. Energy models range from large Integrated Assessment Models (IAMs) that analyse the performance of energy systems in relation to global natural and humans systems; to Energy Systems Models that focus on evaluating how to meet energy targets through different technologies, and; Specialist Models that focus on evaluating specific technologies, impacts or issues.

These different categories of models are designed based on varying overarching objectives that influence the model's scope, the inputs and calculation approach - all of which in turn characterise the capability, strengths and weaknesses of any given model. When policy makers, scientists and analysts use models to investigate energy questions it is important to be aware of the uncertainties and limitations of the models being used, and question whether the models used are suitable for the task.

\subsection{Role of Bioenergy within Energy Strategies}

Energy from biomass is a key component of many country's energy decarbonisation strategies, for example bioenergy and biofuels have been core energy technologies deployed by many EU countries to meet the targets of the Renewable Energy Directive [8]. Bioenergy is an attractive energy option for all stages of development due to its flexibility in the multiple forms of energy and chemicals it may produce, and unlike many other renewables it may provide energy that can be dispatched to balance dynamic demands, has high potential for integration with existing infrastructures and crucially can deliver energy with less greenhouse gas emissions compared to fossil fuel energy pathways [9].

Bioenergy systems contrast to other renewables in that the different steps of a bioenergy system will include links with engineering, natural systems and people - the balance of impacts and benefits to each of these determining the overall performance and sustainability of a bioenergy system. As 
bioenergy is targeted by many national energy strategies, energy policy decision makers need to be aware of wider environmental, economic and socials nuances associated with different bioenergy supply chains and system - this may be achieved through critical assessment of biomass resources and bioenergy processes enabled by models.

\subsection{Review of Biomass \& Bioenergy Research \& its Role in Energy Models}

This review paper has been developed to analyse how bioenergy is treated within IAMs, energy systems models and specialist models. The paper identifies the leading models that are currently most widely applied in developing bioenergy policy and aims to evaluate the performance of these models in capturing the many issues and themes that collectively determine the overall performance of bioenergy systems as sustainable low carbon technology options. A 'Bioenergy Literature Database' has been built to list and characterise the total number of bioenergy research papers published between 2000 and 2018. Analysis of this database allows evaluation of: how the focus of bioenergy research papers has evolved since 2000; the extent that bioenergy modelling is used within published research, and; highlights which models are used to analyse different prominent themes relevant to bioenergy - for example identifying whether a model is capable of assessing the emission performance of bioenergy options. Overall this allows an evaluation of how models are applied and to identify the most appropriate use of different types of models for different purposes, also identifying any gaps that could result in less reliable results.

\section{Methodology}

The methodology section describes the focus of the literature review exercise undertaken within this research, introduces how the Bioenergy Literature Database (BLD) was developed and summarises how the BLD was used to analyse the changing trends and characteristics of bioenergy research. An extended description of the design of the BLD and its analyses are provided in Supplementary Materials 1.

\subsection{Literature Review}

A comprehensive literature review was undertaken to evaluate the different types of energy models and to analyse how they are applied within bioenergy research. This review was completed focusing on published academic literature, Government reports and through engagement with UK academic, government and industry stakeholders at a UK Supergen Bioenergy Hub event [10]. The focus of the literature review was to document the varying approaches that different models have to bioenergy research and to highlight the performance of these models in analysing key bioenergy research questions.

\subsection{Building the Bioenergy Literature Database}

The Bioenergy Literature Database (BLD) database was developed as a research tool to allow analysis of the changing characteristics of bioenergy literature and how these publications use modelling within their methods and analyses. The BLD was designed with the aim of collating a full list of all the bioenergy research papers published between 2000 and 2018. This timeframe was chosen because 2000 represents a time when bioenergy started to gain policy focus and traction as an alternative energy source, whilst 2018 was the last year where a full year's publication record was available at the time of writing this paper.

The BLD was constructed sourcing references from The Web of Science [11], where a systematic process of bioenergy publication searches was completed collating the results of all searches within a Microsoft Excel database (BLD). These searches focused on bioenergy literature that made references to the key words and phrases as listed within Table 1. This list of key search terms and the choice of specific 'high profile' named models included within the searches were developed following consultation with UK academic, government and industry stakeholders at a UK Supergen Bioenergy Hub event [10]. Each research publication entry included within the BLD included capture of key information including the Authors, Title, Year, Host Publication and the Full Abstract. The final BLD captured 124,285 biomass/ bioenergy research papers published between 2000 and 2018. 
Table 1: Search Themes Used within the Web of Science for Building the BLD

\begin{tabular}{|c|c|c|c|c|}
\hline Major Themes & - $\quad$ Biomass & - Bioenergy & & \\
\hline $\begin{array}{l}\text { Integrated } \\
\text { Assessment } \\
\text { Models }\end{array}$ & $\begin{array}{ll}- & \text { AIM/CGE } \\
\text { - } & \text { GCAM }\end{array}$ & $\begin{array}{ll}- & \text { IMACLIM } \\
\text { - } & \text { IMAGE }\end{array}$ & $\begin{array}{ll}\text { - } & \text { MESSAGE-GLOBIOM } \\
\text { - } & \text { REMIND-MAgPIE }\end{array}$ & - WITCH \\
\hline $\begin{array}{l}\text { Energy } \\
\text { System } \\
\text { Models }\end{array}$ & $\begin{array}{ll}\text { - } & \text { AGLINK } \\
\text { - } & \text { BALMOREL } \\
\text { - } & \text { DECC 2050 } \\
& \text { calculator } \\
\text { - } & \text { DER-CAM } \\
\text { - } & \text { DNE21 } \\
\text { - } & \text { DynEMo } \\
- & \text { E4cast } \\
- & \text { EMCAS } \\
\end{array}$ & $\begin{array}{ll}- & \text { EMPS } \\
- & \text { EnergyPLAN } \\
- & \text { ENPEP-BALANCE } \\
- & \text { ESME } \\
- & \text { ETM-UCL } \\
- & \text { FAPRI-CARD } \\
- & \text { GEM-E3 } \\
- & \text { IKARUS } \\
\end{array}$ & $\begin{array}{ll}\text { - } & \text { MERGE-ETL METIS } \\
\text { - } & \text { MiniCAM } \\
\text { - } & \text { PERSOMOSYS } \\
\text { - } & \text { POLES } \\
\text { - } & \text { RAMSES }\end{array}$ & $\begin{array}{ll}\text { - } & \text { SPLAT } \\
\text { - } & \text { TEMOA } \\
\text { - } & \text { TIAM-UCL } \\
\text { - } & \text { TIMER } \\
\text { - } & \text { UK TIMES } \\
\text { - } & \text { WEPS } \\
\text { - } & \text { WILMAR }\end{array}$ \\
\hline $\begin{array}{l}\text { Specialist } \\
\text { Models }\end{array}$ & $\begin{array}{ll} & \text { BRM } \\
- & \text { BVCM } \\
- & \text { CARBINE } \\
- & \text { CO2Fix } \\
- & \text { COMPOSE } \\
\end{array}$ & $\begin{array}{ll} & \text { EFI-GTM } \\
- & \text { EFISCEN } \\
- & \text { GAINS } \\
- & \text { HYDROGEMS } \\
- & \text { INFORSE } \\
\end{array}$ & $\begin{array}{ll}\text { - } & \text { Invert } \\
\text { - } & \text { LEAP } \\
\text { - } & \text { PLEXOS } \\
\text { - } & \text { SHIPMod } \\
\text { - } & \text { TOSIA } \\
\end{array}$ & $\begin{array}{ll}\text { - } & \text { UK Solid \& } \\
& \text { Gaseous } \\
& \text { Biomass Carbon } \\
\text { Calculator } \\
\text { - } \quad \text { WASP } \\
\end{array}$ \\
\hline $\begin{array}{l}\text { Bioenergy } \\
\text { Feedstocks }\end{array}$ & $\begin{array}{ll} & \text { Forestry } \\
\text { - } & \text { Algae } \\
\text { - } & \text { Pellet } \\
\end{array}$ & $\begin{array}{ll} & \text { Chip } \\
- & \text { Wood } \\
- & \text { Waste } \\
\end{array}$ & $\begin{array}{ll}- & \text { Residues } \\
\text { - } & \text { Lignocellulosic } \\
\text { - } & \text { Energy Crops } \\
\end{array}$ & $\begin{array}{ll}- & \text { 1st Generation } \\
- & \text { 2nd Generation } \\
- & \text { 3rd Generation } \\
\end{array}$ \\
\hline $\begin{array}{l}\text { Modelling } \\
\text { Approaches }\end{array}$ & $\begin{array}{l}\text { - } \quad \text { Bottom-Up } \\
\text { - } \quad \text { Top Down } \\
\end{array}$ & $\begin{array}{ll}- & \text { TEA } \\
- & \text { GIS } \\
\end{array}$ & - LCA & - IAM \\
\hline $\begin{array}{l}\text { Bioenergy } \\
\text { Technologies } \\
\text { \& Processes }\end{array}$ & $\begin{array}{ll}\text { - } & \text { BECCS } \\
\text { - } & \text { Combustion } \\
\text { - } & \text { Pyrolysis } \\
\text { - } & \text { Gasification } \\
\end{array}$ & $\begin{array}{ll}\text { - } & \text { Torrefaction } \\
\text { - } & \text { Anaerobic Digestion } \\
\text { - } & \text { Thering } \\
\end{array}$ & $\begin{array}{ll}\text { - } & \text { Catalytic } \\
\text { - } & \text { Biochemical } \\
\text { - } & \text { Fermentation }\end{array}$ & $\begin{array}{ll}- & \text { Drying } \\
\text { - } & \text { Chipping } \\
\text { - } & \text { Pelletising } \\
\end{array}$ \\
\hline $\begin{array}{l}\text { Bioenergy } \\
\text { Systems } \\
\text { Issues }\end{array}$ & $\begin{array}{ll}\text { - } & \text { Bioeconomy } \\
\text { - } & \text { Economics } \\
\text { - } & \text { Emissions } \\
\text { - } & \text { ILUC } \\
\end{array}$ & $\begin{array}{ll}\text { - } & \text { Environment } \\
\text { - } & \text { Carbon } \\
\text { - } & \text { Sustainability } \\
& \text { Climate Change } \\
\end{array}$ & $\begin{array}{ll}\text { - } & \text { Yield } \\
\text { - } & \text { Trade } \\
\text { - } & \text { Water } \\
\text { - } & \text { Deforestation } \\
\end{array}$ & $\begin{array}{ll}\text { - } & \text { Biodiversity } \\
\text { - } & \text { Jobs } \\
\text { - } & \text { land }\end{array}$ \\
\hline $\begin{array}{l}\text { Bioenergy } \\
\text { Vectors }\end{array}$ & $\begin{array}{ll}\text { - } & \text { Power } \\
\text { - } & \text { Heat } \\
\text { - } & \text { Transport }\end{array}$ & $\begin{array}{ll}\text { - } & \text { Aviation } \\
\text { - } & \text { Haulage }\end{array}$ & $\begin{array}{ll}- & \text { Shipping } \\
- & \text { Syngas }\end{array}$ & $\begin{array}{ll}\text { - } & \text { Chemical } \\
\text { - } & \text { Ecosystem } \\
& \text { Services }\end{array}$ \\
\hline
\end{tabular}

\subsubsection{Analysis using the Bioenergy Literature Database}

Building on a methodology developed by Welfle et al [12], this analysis relies on the assumption that key words describing the content of the paper will be included in the abstract. Through creating a tally of the coverage of key search terms, the BLD was used to analyse: the changing number of papers covering different bioenergy issues; the changing use of different types of models, and; to highlight the extent that different models are used to analyse different themes of bioenergy research.

\section{Literature Review - Energy Modelling \& Bioenergy}

Modelling when applied to energy research typically focus on issues of fuel choice, energy technology, costs, location of energy production or consumption, potential innovations and the policy landscape. Energy models can be broadly split into categories based on the modelling technique applied:

- Process Models are deterministic allowing assessment of the feasibility of achieving key energy performance metrics such as mass-energy balance, costs or Greenhouse Gas (GHG) impact, driven by explicit assumptions and the model algorithms. Process models may be iterated to improve/ optimise performance of technologies and related thermodynamic approaches may be used to evaluate optimal performance compared to that of alternative scenarios.

- Econometric Models use historical data that is extrapolated to analyse possible future developments, achieved through analysing the statistical relationship between economic quantities related to a specific economic phenomenon [13]. For example, forecasting the consumption of energy by sectors and the associated emissions linked to economic growth and/ or energy and carbon prices etc. 
Historically the most frequently modelled energy issue are fossil fuels and the extent that these may continue to be used to generate energy. Much of the analysis revolved around fuel reserve estimates and supply/ demand trends, where through application of a series of economic parameters and the premise that the resources are finite, may be used to forecast price and consumption [14]. Approaches and strategies for modelling renewable resources such as bioenergy require a different approach as an additional dynamic exists - the resource reserves can be renewed if managed sustainably. Also given the increased focus placed on measuring the wider impacts of our energy systems such as environmental issues, much bioenergy modelling is undertaken to account and forecast the wider impacts and benefits of different biomass resources and bioenergy technology options [15].

When it comes to modelling bioenergy systems there are a whole range of models that focus on analysing the potential role of bioenergy and its integration, typically analysing one of more of the key stages intrinsic to any bioenergy system:

1) Biomass Resource Feedstocks - that fuel the bioenergy systems are fundamental; as the supply of sustainable resource, consistency, timings and spatial availability of supply will limit the extent that bioenergy may be generated. The types and extent that different resources are available and the production/ mobilisation practices that characterise supply chains are key to the overall performance of a bioenergy system.

2) Bioenergy Conversion Technologies - that generate energy, fuels and other products from different biomass feedstocks; the choice of these technologies and how they are modelled will determine the forms and levels of bioenergy that may be generated, in addition to influencing the economic and environmental performance of the resulting energy vector. These factors ultimately determining the extent that bioenergy may contribute to achieving energy or climate change targets within the framework of different analyses.

3) Wider Systems Issues - unlike many other renewable technologies, the sustainability of bioenergy and biomass feedstocks are often intrinsically linked to multiple natural systems and industry sectors. Many bioenergy feedstocks are by-products of existing processes for example, agriculture, waste management and forestry etc., whilst the production of other bioenergy feedstocks may be highly reliant on availability and access of land, water, food systems and nutrients within the appropriate natural and climatic environment. Thus in contrast to most other renewable technologies, modelling bioenergy systems can present many unique challenges and a need to balance the many interaction and feedback loops between systems.

\subsection{Modelling Categories vs. Modelling Approaches}

There are multiple categories of models currently applied for assessing these different bioenergy themes. These include: i) Integrated Assessment Models (IAM) that analyse the multiple interactions between human and natural systems ii) Energy System Models that are typically technology focused, and iii) Specialist Modelling such as bottom-up analyses that focus on highly specific themes, technologies or processes.

Within each category of model, there are also a range of different approaches that are applied in how they undertake analyses. For example computable general equilibrium (CGE) modelling and partial equilibrium (PE) are typically used to analyse the broad macro-economic impacts of different policy options; specialised bottom-up modelling may apply methods such as life cycle assessment (LCA) analysis, techno-economic analysis (TEA) to test the performance of specific case studies; whilst analysis techniques using geographic information systems (GIS) or developing a Process Model may be used to analyse specific questions around bioenergy technologies or supply chains. Each of the key modelling categories and approaches in relation to bioenergy research are discussed in the following section of the literature review. 


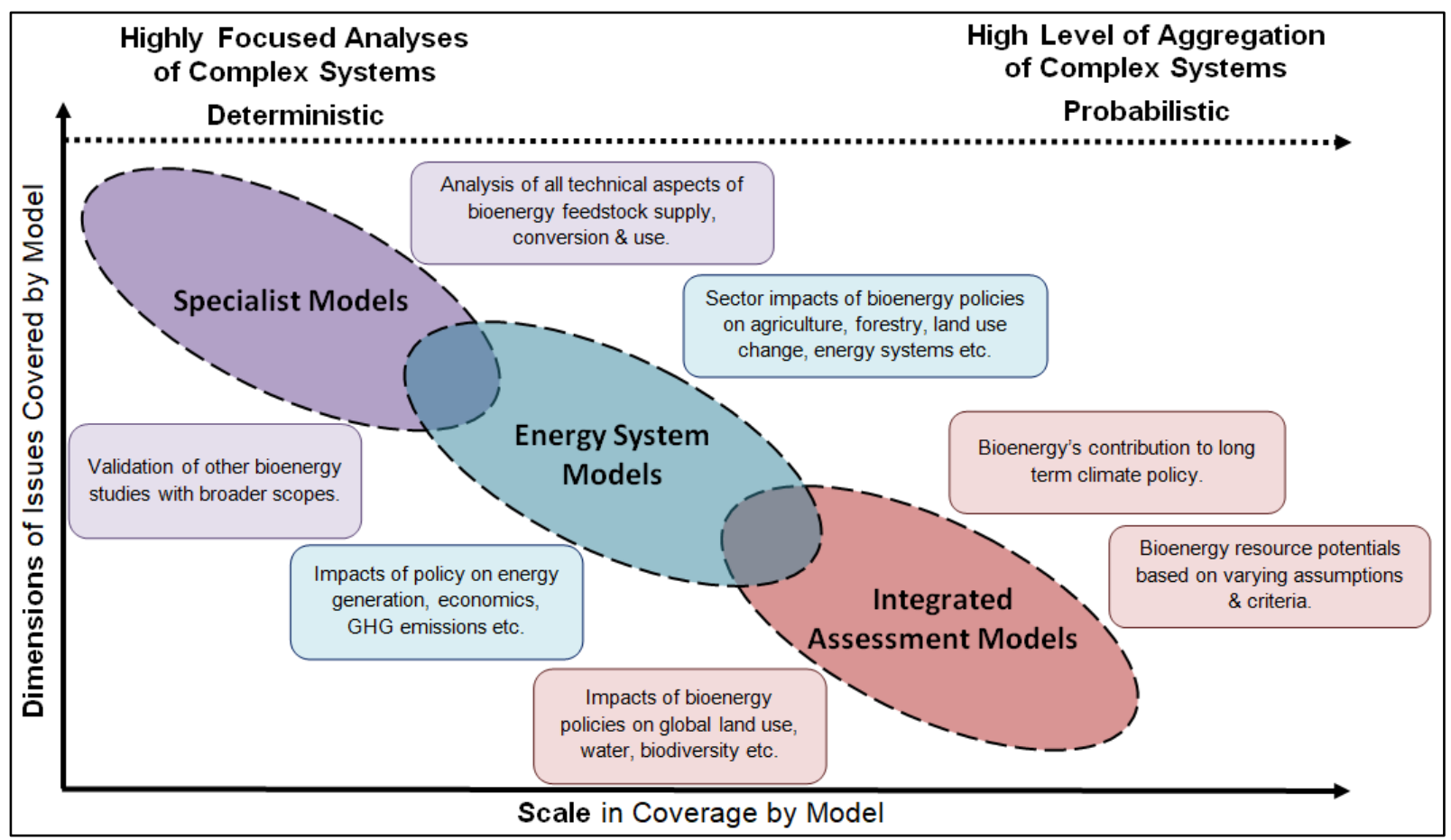

Figure 1 provides a summary of the characteristics and typical approaches of the main categories of models covered by this paper, also highlighting the influence this has on the types of bioenergy

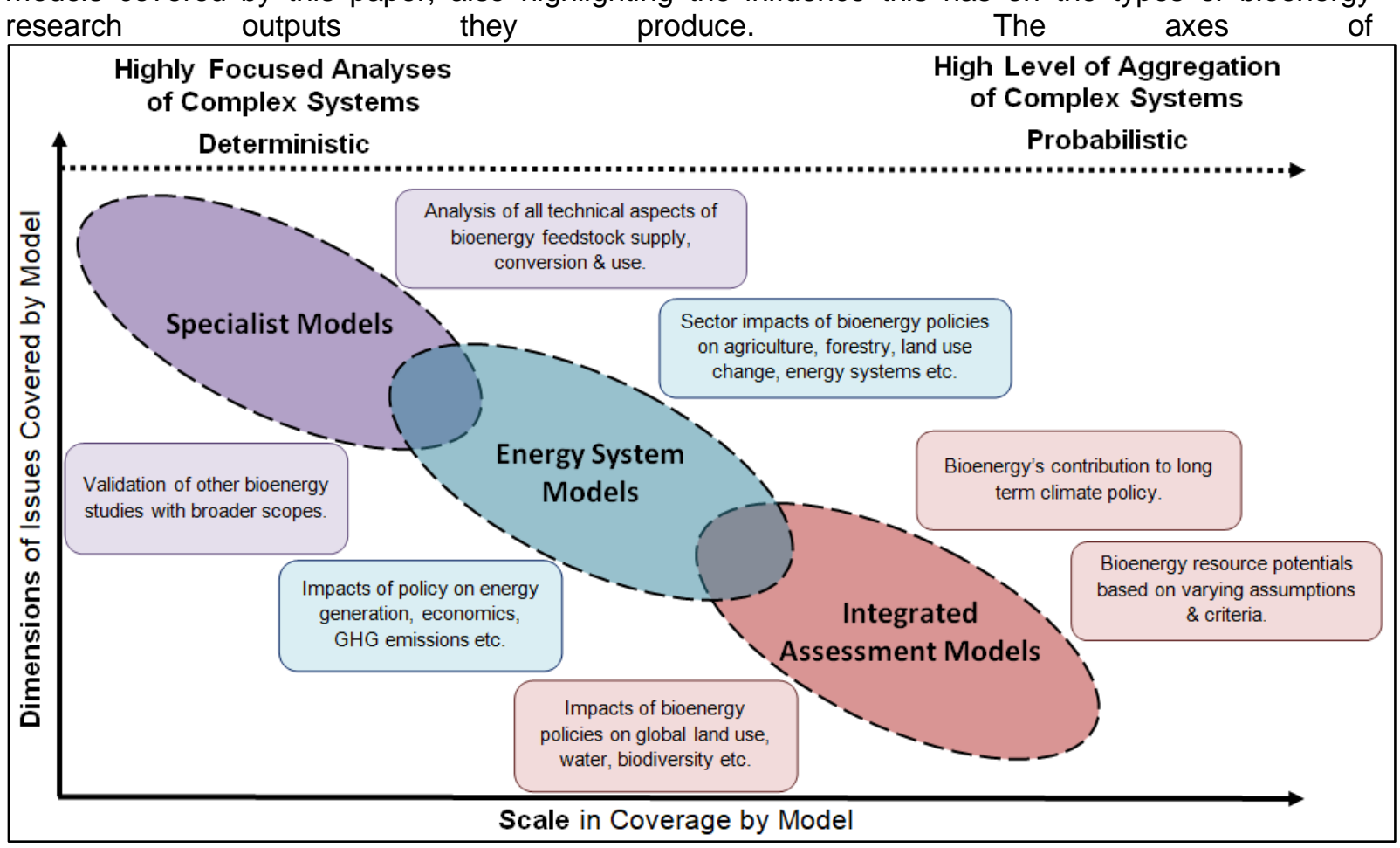

Figure 1 document the scale and dimensions to which the different categories of model focus. IAMs focus on large global scale analyses whilst specialist models are often highly focuses on specific bioenergy issues. Whilst the global nature of IAMs means they have to keep narrow dimensions of issues they can analyse, albeit doing these on a large scale, in contrast to the large number of dimensions specialist models can address through highly focused specialist analyses. 


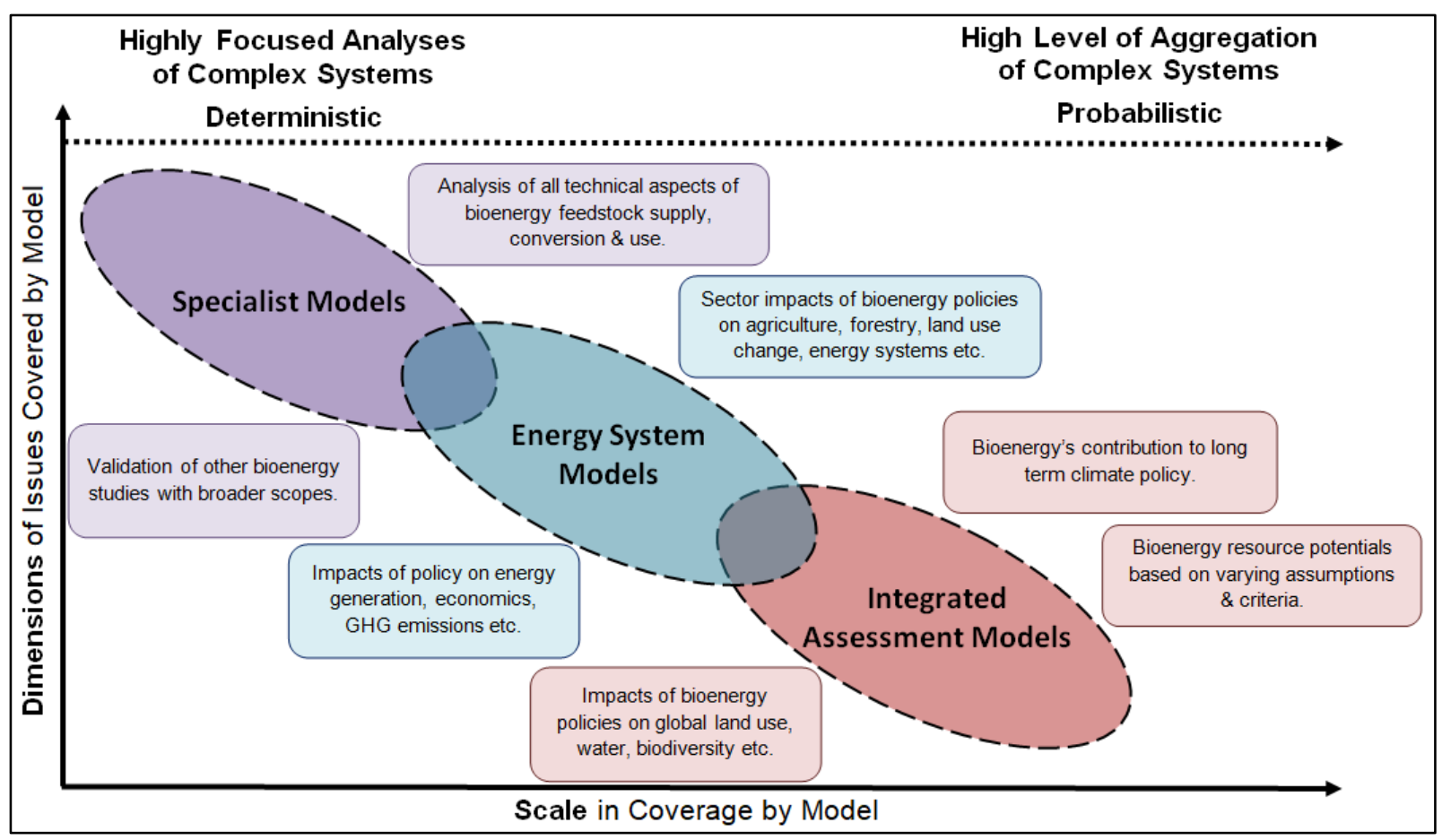

Figure 1: Energy Modelling Categories and their Approaches \& Capability for Bioenergy Analyses

It is also important to highlight the role of 'model comparison projects' (MIPs), which are undertaken to identify the range of outcomes that different models generates and to build an understanding of why there are (sometimes large) variances. These projects are important as they increase awareness of the drivers behind different models results and consequently increase their usefulness. Examples of MIPs include: Slade et al (2011) [16] who analysed global biomass resource models and evaluated the drivers that influenced the differences between the outs of models; Rose et al. (2014) [17] carried out an extensive comparison of IAMs; Bauer et al. (2018) [18] who analysed IAM focusing on their coverage of biomass and bioenergy; and targeted studies such as that by Lotze-Campen et al. (2014) [19] compared agricultural system drivers and how these are crucial to IAM projections related to bioenergy.

\subsection{Energy Systems Models \& Specialist Bioenergy Models}

The first energy systems models were developed in the 1970's at a time when electricity was delivered largely by the grid, generated solely from fossil fuel technologies and where there was no need for energy storage. The objective of these models was largely to ensure system stability amidst backdrop of potential fluctuations in fossil fuel availability due to geopolitical influences.

With the emergence of the climate change agenda and exponential growth of renewable technologies, there has been a reflective rise in the number and capability of energy system models that have been designed to analyse and deal with the new dynamics associated with the sometimes highly variable mixed technology energy systems we have today [20]. Energy models are now crucial in providing the evidence required to inform policy decisions that are driving the transition towards increasingly sustainable and low carbon energy systems [21]. As Table 2 highlights energy system models may be applied to analyse very detailed aspects of energy systems and most models allow evaluation of multiple technologies or scenario settings. There are a number of modelling approaches that are typically applied according to the types of energy systems analyses desired, these include: bottom-up optimisation models such as applied within the MARKAL model; bottom-up accounting models as used within the LEAP model; top-down econometric models such as the DTI energy model; hybrid models such as used within the POLES model; and planning focused models such as used for electricity planning within the WASP model. 

Table 3 provides a comparison of these different modelling approaches summarising the range of typical characteristics associated with each.

Table 2: Range of Approaches and Themes Covered by Energy System Models

\begin{tabular}{|c|c|c|}
\hline \multirow{7}{*}{$\begin{array}{c}\text { Purpose \& } \\
\text { Structure }\end{array}$} & Purpose of the Model: & Forecasting, Exploring, Backcasting \\
\hline & Analysis Themes: & $\begin{array}{c}\text { Energy, Demand, Energy supply, Impacts, Environmental, Appraisal, Integrated } \\
\text { approach, Modular build-up }\end{array}$ \\
\hline & Structure of Models: & $\begin{array}{l}\text { Degree of endogenization, Description of non-energy sectors, Description of end- } \\
\text { uses, Description of supply technologies, Supply or Demand analysis tool }\end{array}$ \\
\hline & Geographical Coverage: & Global, Regional, National, Local/ community, Single-project \\
\hline & Sectoral Coverage: & Energy sectors, Other specific sectors, Overall economy \\
\hline & Time Horizons: & Short, Medium, Long Term \\
\hline & Time Steps: & Minutely, Hourly, Monthly, Yearly, Five-yearly, User-defined \\
\hline \multirow{6}{*}{$\begin{array}{l}\text { Technologies } \\
\text { \& Sectors } \\
\text { Analysed }\end{array}$} & Renewable Technologies: & HydroSolar (PV and thermal), Geothermal, Wind, Wave, Biomass, Tidal \\
\hline & $\begin{array}{l}\text { Storage Technology } \\
\text { Inclusion: }\end{array}$ & $\begin{array}{c}\text { Pumped-hydro energy storage, Battery energy storage, Compressed-air energy } \\
\text { storage, Hydrogen production/storage/ consumption }\end{array}$ \\
\hline & Transport Demands: & $\begin{array}{c}\text { Internal-combustion vehicles, Battery-electric vehicles, Vehicle-to-grid electric } \\
\text { vehicles, Hydrogen vehicles, Hybrid vehicles, Rail Aviation }\end{array}$ \\
\hline & Residential Demands: & Heating, Lighting, Cooking, Appliance usage, Smart Appliances \& Smart metres \\
\hline & Commercial Demands: & Offices, Warehousing, Retail \\
\hline & Cost Inclusion: & $\begin{array}{l}\text { Fuel prices, Fuel handling, Investment, Fixed Operation \& Maintenance (O\&M), } \\
\text { Variable Operation \&Maintenance }(\mathrm{O} \& M), \mathrm{CO}_{2} \text { costs }\end{array}$ \\
\hline \multirow{4}{*}{$\begin{array}{l}\text { Methods \& } \\
\text { Approaches }\end{array}$} & Analytical Approaches: & Top-Down, Bottom-Up, Hybrid, Other \\
\hline & Underlying Methodologies: & $\begin{array}{c}\text { Econometric, Macro-Economic, Micro-Economic, Economic Equilibrium, } \\
\text { Optimization, Simulation, Stochastic/Monte-Carlo, Spatial (GIS), } \\
\text { Spreadsheet/Toolbox, Backcasting, Multi-Criteria, Accounting }\end{array}$ \\
\hline & Mathematical Approaches: & $\begin{array}{c}\text { Linear programming, Mixed-integer, programming Dynamic programming, Fuzzy } \\
\text { logic, Agent based programming }\end{array}$ \\
\hline & Data Requirements: & Qualitative, Quantitative, Monetary, Aggregated, Disaggregated \\
\hline
\end{tabular}


Table 3: Comparison of Energy System Modelling Approaches \& Typical Model Characteristics

\begin{tabular}{|c|c|c|c|c|c|}
\hline \multirow[b]{2}{*}{ Model Characteristics } & \multicolumn{5}{|c|}{ Energy System Modelling Approach } \\
\hline & $\begin{array}{l}\text { Bottom-Up } \\
\text { Optimisation }\end{array}$ & $\begin{array}{l}\text { Bottom-Up } \\
\text { Accounting }\end{array}$ & $\begin{array}{l}\text { Top-Down } \\
\text { Econometric }\end{array}$ & Hybrid & Planning \\
\hline Geographical Scale & $\begin{array}{l}\text { Local to Global, } \\
\text { mostly National }\end{array}$ & $\begin{array}{l}\text { Mostly National, } \\
\text { can be Regional }\end{array}$ & National & $\begin{array}{l}\text { National or } \\
\text { Global }\end{array}$ & National \\
\hline Themes & $\begin{array}{c}\text { Energy Systems, } \\
\text { Environment, } \\
\text { Trading }\end{array}$ & $\begin{array}{l}\text { Energy Systems, } \\
\text { Environment }\end{array}$ & $\begin{array}{c}\text { Energy Systems, } \\
\text { Environment }\end{array}$ & $\begin{array}{c}\text { Energy Systems } \\
\text { Hybrid }\end{array}$ & $\begin{array}{c}\text { Energy Systems, } \\
\text { Electricity } \\
\text { Planning }\end{array}$ \\
\hline Time horizon & $\begin{array}{l}\text { Medium to Long- } \\
\text { Term }\end{array}$ & $\begin{array}{l}\text { Medium to Long- } \\
\text { Term }\end{array}$ & $\begin{array}{l}\text { Short, Medium or } \\
\text { Long-Term }\end{array}$ & $\begin{array}{l}\text { Medium to Long- } \\
\text { Term }\end{array}$ & $\begin{array}{c}\text { Medium to Long- } \\
\text { Term }\end{array}$ \\
\hline Data Requirement & Extensive & $\begin{array}{l}\text { Extensive but } \\
\text { can Work with } \\
\text { Limited Data }\end{array}$ & High & $\begin{array}{l}\text { High to } \\
\text { Extensive }\end{array}$ & Extensive \\
\hline $\begin{array}{c}\text { Data } \\
\text { Disaggregation }\end{array}$ & High & High & Varied & High & $\mathrm{N} / \mathrm{A}$ \\
\hline $\begin{array}{c}\text { Technologies } \\
\text { Modelled }\end{array}$ & Extensive & $\begin{array}{l}\text { Extensive but } \\
\text { Pre-defined }\end{array}$ & $\begin{array}{l}\text { Variable but } \\
\text { Typically Limited }\end{array}$ & $\begin{array}{l}\text { Extensive but } \\
\text { Pre-defined }\end{array}$ & Extensive \\
\hline $\begin{array}{l}\text { Modeller Skill } \\
\text { Requirement }\end{array}$ & Very High & High & Very High & Very high & Very High \\
\hline $\begin{array}{l}\text { Computing } \\
\text { Requirement }\end{array}$ & High End & Not Demanding & $\begin{array}{c}\text { Econometric } \\
\text { Software } \\
\text { Required }\end{array}$ & $\begin{array}{l}\text { Potential } \\
\text { Commercial } \\
\text { Software } \\
\text { Requirement }\end{array}$ & $\begin{array}{l}\text { Potential } \\
\text { Commercial } \\
\text { Software } \\
\text { Requirement }\end{array}$ \\
\hline $\begin{array}{l}\text { Capability to Analyse } \\
\text { Price-Induced Policies }\end{array}$ & High & $\mathrm{N} / \mathrm{A}$ & High & $\begin{array}{l}\text { Typically } \\
\text { Available }\end{array}$ & Available \\
\hline $\begin{array}{l}\text { Capability to Analyse } \\
\text { Non-Price Policies }\end{array}$ & Good & Very Good & Very Good & Very Good & Good \\
\hline $\begin{array}{l}\text { New Technology } \\
\text { Addition }\end{array}$ & Possible & Possible & Difficult & $\begin{array}{l}\text { Possible but } \\
\text { Limited }\end{array}$ & Possible \\
\hline $\begin{array}{c}\text { Informal Sector } \\
\text { Analysis }\end{array}$ & Difficult & Possible & Difficult & Possible & Difficult \\
\hline
\end{tabular}

\subsubsection{Computable General Equilibrium (CGE) Modelling \& the Relationship with Bioenergy}

Computable general equilibrium (CGE) models are widely applied to energy analyses to evaluate the effects of climate policies. CGE models are well suited to study bioenergy policies as their key characteristic is their encompassing scope - global CGE models cover the world economy disaggregated into countries, regions, individual sectors and specific economic activities. CGE models focus on identifying and assessing the direct and indirect feedback effects of certain policies or shocks across these sectors and countries etc [23].

Analyses using these models focus on measuring the disruption to this equilibrium and the processes of achieving new balances following interventions such as the introduction of a new policy regime. The strengths of modelling analyses using the CGE approach stems from the depth of linkages and relationships that CGE models have between different economic sector markets. These linkages mean the wider impacts of policy interventional across multiple sectors can be analysed providing policy makers with valuable insights to the potential overall economic impacts of policy interventions.

CGE modelling approaches have been widely used to analyse the implications of biomass and bioenergy policies associated with the economics of different sectors and potential influencing forces these have on issues such as land use change [24]. CGE models are particularly useful when 
analysing the impacts of strategies for significant bioenergy deployments in the short to medium terms, when the modelling results may be used to identify the immediate impacts on different economic sectors such as agriculture or industry [25].

Through linking with groups such as the Global Trade Analysis Project (GTAP) research consortium, there are many examples where a CGE modelling approach has been used to analyse bioenergy themes such as for evaluating the influence of bioenergy policy on development of the bio-economy [26], or assessing the wider impacts of increased focus on biofuel production [27].

CGE modelling has been most influential for the bioenergy sector when focused on production of $1 \mathrm{st}$ Generation energy crops, where analyses has highlighted the influence of this practice on national and international food markets [28], changes on commodity prices [29], on land use change [30], societal impacts [27] and GHG emissions both directly generated as a consequence of the bioenergy systems and through offsetting the use of fossil fuel alternatives [31].

\subsubsection{Partial Equilibrium (PE) Modelling \& the Relationship with Bioenergy}

PE models follow the same economic framework as CGE models but only cover selected economic sectors. This can provide both advantages over CGE models with the potential for increasing levels of flexibility and added details to analysis of the sectors that are covered, and disadvantage in that the outputs from PE will be limited with absent representations of non-included sectors.

PE models are therefore adopted to analyse specific research questions where the impacts on certain sectors are desired such as to agriculture or energy. In the context of bioenergy research this could be to analyse the primary effects of a new policy intervention on a particular feedstock market. PE models are applied successfully for both short to medium term analysis timeframes where the objective is to gain market outlooks such as with the OECD's FAPRI-CARD and AGLINK models, also for long-term analyses timeframes such as within GLOBIOM where the timeframe can stretch to 2100 [24].

The MARKAL family of models represents some of the most widely applied energy system models for bioenergy analysis using a PE modelling approach. These models provide a technology rich analysis platform that driven by assumptions such as the costs and performance of energy generation and infrastructure will produce energy supply options for achieving end-point targets. This approach of recommending energy systems based on an optimisation approach has been widely applied in bioenergy research to evaluate scenarios for how bioenergy may be used within different areas of the energy sector [32]; the limits of bioenergy within different geographies based on varying sustainability constraints [33]; demonstrating how bioenergy may be used in complement to other renewable technologies as energy systems transitions towards low carbon energy mixes [34]; and increasingly how to best use and maximise the value of available biomass resource [35].

\subsubsection{Bottom-up Analyses \& Modelling \& the Relationship with Bioenergy}

Analyses within models applying a bottom-up approach are typically highly specialised and focus on detailed evaluations of specific technologies, processes, resources and their resulting environmental/ cost/ energy/ impacts. In contrast to CGE and PE models, bottom-up analyses do not normally undertake the equivalent detailed analysis of economic markets so the wider impact on these are not captured, but they instead focus on providing detailed measurements of performances for specific processes, activities or interventions. The specialist focus of these models means they typically apply accurate current data relevant to performances within a defined analysis boundary.

There are multiple subgroup approaches that are widely applied within bioenergy research that typically assess biomass resource and bioenergy generation potential and the performance impacts of related processes, examples include: Process-based technical models to test the function of performance of systems [36]; Process-based biophysical models to assess crop suitability and growth [37]; Bioenergy sustainability indicator models to evaluate performance of systems against specific environmental/ social criteria [38]; Life-cycle analysis modelling to analyse the environmental footprint of bioenergy systems and supply chains [39]; Biomass resource models assessing feedstock availability within geographies [40]; Land use management models to analyse impacts of using different land types; Feedstock supply chain models to evaluate the performance of supply chains [41]; Techno-economic models to assess the potential costs of different technology option [42], and; Feedstock and bioenergy supply and demand mapping [9].

Wicke et al [24] highlights both the advantages and disadvantages of bottom-up derived analysis from a bioenergy research perspective through a case study of GHG analysis: life-cycle analysis (LCA) 
studies are widely carried out to evaluate the GHG performances of bioenergy systems, each study typically identifying both the levels and extent that different GHGs are generated by each step within a given lifecycle and thus highlighting the overall GHG performance of a system and where improvement actions may be targeted. However the restriction of such analyses to narrow systems boundaries will always provide limited results as indirect effects such as potential indirect land-use change cannot always be captured, and these sometimes having far larger GHG implications than the direct activities taking place within the energy system. Thus Wicke et al conclude that specialist models should be used as a complement to results generated by IAM and energy system models that take account of wider systems.

\subsection{Integrated Assessment Models}

Integrated Assessment Models (IAMs) are computer models developed to analyse the potential evolution of global energy systems alongside other large GHG sources such as agriculture, land use and the characteristics of economies. Analysis scenarios within IAMs are developed based on assumptions around economic and population dynamics and changes to wider ranging GHG sources and sinks. IAMs typically build from baseline scenarios that predict performance based on the continuation of trends of implementation of policy targets. Subsequent scenarios are then developed to provide alternative potential pathways to drive performance beyond the baseline to achieve targets such as achieving reduced GHG emissions or to limit global temperature changes to within specified goals [43].

\subsubsection{Key IAM's}

There have been approximately 20 global scale IAMs developed to date which can be broadly categorised into two groups: i) Detailed Process (DP) IAMs, that focus on quantifying future development pathways to provide detailed sector information of complex processes, and; ii) BenefitCost (BC) IAMs that aggregate the costs of climate change and mitigation activities to estimate the total costs of different climate change impacts [44]. Table 4 provides an introduction and overview of 8 of the most influential IAMs that generate outputs widely cited by organisations such as the Intergovernmental Panel on Climate Change (IPCC).

IAMs share common approaches (land-use, energy system supply \& demands, GHG emissions, fossil fuels, renewables, commodity trade etc), are based on similar assumptions (population, economic growth, inequality, GHG budget and targets, technology options etc), and generate similar outputs (energy technology choices, land-use change, emissions pathways, energy/ food dynamics, climate feedbacks etc). Those listed in the Table 4 represent the approaches, themes, assumptions and outputs where research publications using each of included IAMs have focused [45-52].

\subsubsection{Application \& Impact of IAMs}

The primary role of IAMs is to evaluate the feasibility of achieving goals based on technological and economic parameters [53]. IAMs are therefore valuable tools for supporting decision makers and for informing policy development to support pathways to achieve targeted goals. The leading example where IAMs are currently applied is within climate modelling applications - much of the global scale analysis on climate mitigation and evaluation of pathways to achieve climate targets such as those of the Paris Agreement [1] has to date been heavily reliant on the outputs of IAMs. Since the IPCC's Second Assessment Report in 1996, outputs from IAMs have underpinned all the IPCC's major analysis themes and recommendations [43].

The results of these analyses are highly influential informing the targets and policy frameworks of Governmental and Organisations worldwide. IAMs therefore remain critically important and influential, and if supplemented and paired with specialist targeted studies will remain the primary 'go-to' tool for climate analyses [54].

\subsubsection{Relationship of IAMs with Bioenergy}

As IAMs are designed to forecast and analyse the long term interactions between land-use, agricultural, energy and climate systems, IAMs may therefore be applied to plot biomass supply and demand pathways taking account of changing dynamics of global systems and the many interactions between these [55]. Bioenergy forecasts from IAMs therefore not only take account of the implications from changing energy systems, but can also provide biomass resource supply forecasts that account for the limitations, trade-offs and synergies between different natural systems - such as the influence of changing dynamics from water, land use, temperature and the global carbon cycles [24]. 
There are many examples where IAMs have been used to analyse the long term implications for bioenergy supply potentials based on changing global land use dynamics [56], or based on changing global water availability and biodiversity [57]. The premise of many of these IAM bioenergy analyses is to forecast biomass resource potentials based on designed sustainability constraints that will influence biomass availability. Through applying a series of macro level assumptions of the types and scale of biomass resource that may be produced on different categories of land, and through excluding lands deemed unsuitable, IAMs have been extensively used to calculate global tonnes/ $\mathrm{yr}^{-1}$ of biomass or $\mathrm{EJ} / \mathrm{yr}^{-1}$ of bioenergy that may be generated. However, bioenergy and biomass resource forecasts from IAMs can vary significantly. Comparison of the forecasts of different analysis scenarios from studies using both the same and different IAMs highlight wide reaching forecast ranges, these differences driven largely by the parameters and constraints applied within each scenario. An example is provided by Chum et al. [58], who place the bioenergy potential from all land-based bioenergy resources at between 50-1000 $\mathrm{EJ} \mathrm{yr}^{-1}$.

The study undertaken by Bauer et al (2018) [18] carried out a comparison of 11 global long-term IAMs in relation to their assessment of potential $\mathrm{CO}_{2}$ emissions that may be achieved through scenarios where there is wide scale deployment of advanced bioenergy technologies. The assumptions identified as the most important for driving bioenergy deployment were the cost and availability of bioenergy conversion technologies, the potentials and constraints of feedstocks and the characteristics of the baseline scenarios that determine the sector specific and overall targets for emission mitigations. Through comparing the scenarios from these different IAMs and where their assumptions were varied to reflect different global scale assessments, the study documents the wide range of values IAMs generate from different bioenergy deployment scenarios. In their conclusions Bauer et al highlight the 'broad room for manoeuvring' that bioenergy can provide for emission strategies, assuming technologies and policies are developed that take account of the sensitivities that will influence growth of a sustainable bioenergy sector.

Through the use of IAMs by the IPCC and the inclusion of net negative emission technologies within many IPCC scenarios, IAMs have become intrinsically linked to and reliant upon large scale bioenergy with carbon capture and storage (BECCS) as the mechanism for achieving large scale rapid reductions in emissions [59]. Much bioenergy analyses using IAMs also focus on assessing the extent that bioenergy may contribute to energy strategies to meet climate change targets. Within these bioenergy studies the technical limits of biomass resource growth/mobilisation are calculated and linked to calculations that compare the costs of bioenergy technology deployment to other energy technologies within the context of a pre-determined policy regime. Restricted by current estimates of cost and GHG life cycle data related to the growth/ mobilisation and supply of different types of biomass resource, in addition to the long analysis timeframes; bioenergy scenarios from IAMs will typically favour large scale use of agricultural and forestry residues, and lignocellulosic energy crops with limited or no production of 1st generation energy crops. Current cost and GHG implications of 1st generation energy crops typically performing less well than alternative bioenergy or alternative renewable technologies for delivering cost effective pathways to achieving climate targets. 
Table 4: Summary of the Design \& Characteristics of Prominent Integrated Assessment Models

\begin{tabular}{|c|c|c|c|c|c|c|}
\hline Model & Themes & Time & Assumptions & Coverage of & ioenergy Issues ${ }^{1}$ & Outputs \\
\hline $\begin{array}{c}\text { AIM / CGE [45] } \\
\text { Asia-Pacific Integrated Model/Computable } \\
\quad \text { General Equilibrium } \\
\text { Regional model analysing policy options for } \\
\text { stabilising global climate \& reducing impacts } \\
\text { through reducing GHG emissions. }\end{array}$ & $\begin{array}{l}\text { - GHG Emission } \\
\text { Modelling } \\
\text { - Global Climate } \\
\text { Change Impact } \\
\text { Modelling }\end{array}$ & $\begin{array}{l}2005- \\
2100\end{array}$ & $\begin{array}{l}\text { - Policy Options } \\
\text { - GHG (Emissions \& } \\
\text { - Atmospheric Concentrations) } \\
\text { - Atmospheric Temperature } \\
\text { - Climate Impacts on Natural } \\
\text { Systems }\end{array}$ & $\begin{array}{l}\text { - } \text { Biomass \& Bioenergy } \\
\text { - } \text { Forestry } \\
\text { - Wastes } \\
\text { - BECCS \& CCS } \\
\text { - Bio-economy }\end{array}$ & $\begin{array}{l}\text { - Environment } \\
\text { - Emissions \& GHGs } \\
\text { - Forestation \& Deforestation } \\
\text { - Land Use }\end{array}$ & $\begin{array}{l}\text { - } \text { Macro-Economy } \\
\text { - } \text { Population \& Labour } \\
\text { - } \text { Energy Supply \& Demands } \\
\text { - } \text { Agriculture \& Land Use }\end{array}$ \\
\hline $\begin{array}{c}\text { GCAM [46] } \\
\text { Global Change Assessment Model } \\
\text { Dynamic-recursive model designed to } \\
\text { explore climate change mitigation policies } \\
\text { e.g. taxes, trade, regulations \& technologies. }\end{array}$ & $\begin{array}{l}\text { - Energy Dynamics } \\
\text { - Economic Dynamics } \\
\text { - Land Use Dynamics } \\
\text { - Water } \\
\text { - Climate Modelling }\end{array}$ & $\begin{array}{l}1990- \\
2100\end{array}$ & $\begin{array}{l}\text { - Energy Supply \& Demand } \\
\text { - GHGs Aerosol Emissions } \\
\text { - Radiative Forcing } \\
\text { - Climate Effects }\end{array}$ & $\begin{array}{ll}\text { - } & \text { Biomass \& Bioenergy } \\
\text { - } & \text { Forestry } \\
\text { - Wastes \& Residues } \\
\text { - } \text { BECCS \& CCS } \\
\text { - Bio-economy \& Trade }\end{array}$ & $\begin{array}{l}\text { - Environment } \\
\text { - Emissions \& GHGs } \\
\text { - Forestation \& Deforestation } \\
\text { - Ecosystems \& Biodiversity } \\
\text { - Land Use }\end{array}$ & $\begin{array}{l}\text { - Population } \\
\text { - Economy } \\
\text { - Technology } \\
\text { - Climate Policy }\end{array}$ \\
\hline $\begin{array}{l}\text { IMACLIM [47] } \\
\text { Global multi-sectoral economic model } \\
\text { combining a Computable General } \\
\text { Equilibrium framework with bottom-up } \\
\text { sectoral modules. }\end{array}$ & $\begin{array}{l}\text { - Transport } \\
\text { - Oil Supply } \\
\text { - Electricity } \\
\text { - Industry } \\
\text { - Energy Efficiency } \\
\end{array}$ & $\begin{array}{l}2001- \\
2100\end{array}$ & $\begin{array}{l}\text { - Economy-Energy- } \\
\text { Environment Scenarios } \\
\text { - Evolution of technologies } \\
\text { - Energy Demand Behaviours } \\
\text { - Economic growth } \\
\end{array}$ & $\begin{array}{ll}\text { - } & \text { Biomass \& Bioenergy } \\
\text { - } & \text { Forestry } \\
\text { - Wastes \& Residues } \\
\text { - } \text { BECCS \& CCS } \\
\text { - } \text { Bio-economy \& Trade } \\
\end{array}$ & $\begin{array}{l}\text { - Environment } \\
\text { - Emissions \& GHGs } \\
\text { - Forestation \& Deforestation } \\
\text { - Ecosystems \& Biodiversity } \\
\text { - Land Use }\end{array}$ & $\begin{array}{l}\text { Economic Dynamics (prices, } \\
\text { quantities, investments) } \\
\text { Technical \& Structural } \\
\text { Parameters (coefficients, } \\
\text { population, productivity) } \\
\end{array}$ \\
\hline $\begin{array}{c}\text { IMAGE [48] } \\
\text { Integrated Model to Assess the Global } \\
\text { Environment } \\
\text { Model focused on long-term dynamics \& } \\
\text { impacts of global change from interacting } \\
\text { socio-economic and environmental factors. }\end{array}$ & $\begin{array}{l}\text { - Human Activity } \\
\text { - Biosphere } \\
\text { - Climate system } \\
\text { - Biodiversity } \\
\text { - Water }\end{array}$ & $\begin{array}{l}\text { Present } \\
-2100\end{array}$ & $\begin{array}{l}\text { - Socio-Economic Pathways, } \\
\text { - Energy, Land \& Water } \\
\text { Impacts } \\
\text { - Unintended Side Effects to } \\
\text { Systems } \\
\text { - Depletion of Resources }\end{array}$ & $\begin{array}{ll}\text { - } & \text { Biomass \& Bioenergy } \\
\text { - } & \text { Wastes \& Residues } \\
\text { - } & \text { BECCS \& CCS } \\
\text { - } & \text { Bio-economy \& Trade } \\
\text { - Environment }\end{array}$ & $\begin{array}{l}\text { - Emissions \& GHGs } \\
\text { - } \text { Forestation \& Deforestation } \\
\text { - } \text { Ecosystems \& Biodiversity } \\
\text { Land Use }\end{array}$ & $\begin{array}{l}\text { - Population } \\
\text { - Economic \& Trade Dynamics } \\
\text { - Policy } \\
\text { - Energy \& Technologies } \\
\text { - Land Use Choices }\end{array}$ \\
\hline $\begin{array}{l}\text { MESSAGE-GLOBIOM [49] } \\
\text { Flexible framework for assessing energy } \\
\text { challenges and scenarios, with focus on } \\
\text { socio-economic \& technological challenges. }\end{array}$ & $\begin{array}{l}\text { - Future Uncertainties } \\
\text { - Technology } \\
\text { Strategy } \\
\text { Development } \\
\text { - Investment for } \\
\text { Policy Objectives. } \\
\end{array}$ & $\begin{array}{l}1971- \\
2100\end{array}$ & $\begin{array}{l}\text { - Domestic Resources Use } \\
\text { - Energy Imports, Exports \& } \\
\text { Trade } \\
\text { - Monetary Flows \& Investment } \\
\text { - GHG \& Aerosol Emissions } \\
\text { - Energy Demand Dynamics } \\
\end{array}$ & $\begin{array}{l}\text { - } \text { Biomass \& Bioenergy } \\
\text { - } \text { Forestry } \\
\text { - Wastes \& Residues } \\
\text { - BECCS \& CCS } \\
\text { - Bio-economy \& Trade }\end{array}$ & $\begin{array}{l}\text { - Environment } \\
\text { - Emissions \& GHGs } \\
\text { - Forestation \& Deforestation } \\
\text { - Ecosystems \& Biodiversity } \\
\text { - Land Use }\end{array}$ & $\begin{array}{l}\text { - Emission Constraints } \\
\text { - Policy Measures } \\
\text { - Taxes \& Subsidies } \\
\text { - Technology Options } \\
\text { - Energy Resources }\end{array}$ \\
\hline $\begin{array}{l}\text { REMIND-MAgPIE [50] } \\
\text { Regional Model of Investments \& } \\
\text { Development } \\
\text { Global multi-regional model incorporating } \\
\text { economic, climate system and the energy } \\
\text { sector. }\end{array}$ & $\begin{array}{l}\text { - Economy \& } \\
\text { Demand } \\
\text { - Technologies } \\
\text { - Energy Systems } \\
\text { - Land Use } \\
\text { - Climate }\end{array}$ & $\begin{array}{l}2005- \\
2100\end{array}$ & $\begin{array}{l}\text { - Welfare } \\
\text { - Energy System Costs } \\
\text { - Agriculture, Forestry \& } \\
\text { Bioenergy Supply } \\
\text { - GHG \& Aerosols } \\
\text { - Atmospheric Temperature }\end{array}$ & $\begin{array}{l}\text { - Biomass \& Bioenergy } \\
\text { - } \text { Forestry } \\
\text { - Wastes \& Residues } \\
\text { - BECCS \& CCS }\end{array}$ & $\begin{array}{l}\text { - } \text { Bio-economy } \\
\text { - Environment } \\
\text { - Emissions \& GHGs } \\
\text { - Ecosystems \& Biodiversity } \\
\text { - Land Use }\end{array}$ & $\begin{array}{l}\text { - } \text { Labour } \\
\text { - } \text { Energy Efficiency } \\
\text { - Resource Constraints \& Trade } \\
\text { - } \text { Agriculture \& Forestry } \\
\text { - } \text { GHG \& Aerosols } \\
\text { - Atmospheric Temperature }\end{array}$ \\
\hline $\begin{array}{l}\text { TIAM [51] } \\
\text { TIMES Integrated Assessment Model } \\
\text { Technology rich, bottom-up model applying } \\
\text { an engineering \& economic approach to } \\
\text { produce a least-cost energy system. }\end{array}$ & $\begin{array}{l}\text { - Demands } \\
\text { - Technologies } \\
\text { - Commodities Trade } \\
\text { - Emissions } \\
\text { - Climate }\end{array}$ & $\begin{array}{c}50 \text { year } \\
\text { timefram } \\
e\end{array}$ & $\begin{array}{l}\text { - Energy Costs } \\
\text { - GHG emissions } \\
\text { - Technology Capacities } \\
\text { - Marginal Emissions } \\
\text { Abatement Costs }\end{array}$ & $\begin{array}{l}\text { - Biomass \& Bioenergy } \\
\text { - } \text { Forestry } \\
\text { - Wastes \& Residues } \\
\text { - BECCS \& CCS } \\
\text { - Bio-economy \& Trade }\end{array}$ & $\begin{array}{l}\text { - Environment } \\
\text { - Emissions \& GHGs } \\
\text { - Forestation } \\
\text { - Ecosystems \& Biodiversity } \\
\text { - Land Use }\end{array}$ & $\begin{array}{l}\text { - Energy (Generation, Demands, } \\
\text { Prices) } \\
\text { - Technology Choices } \\
\text { - Emissions (Levels, Prices) } \\
\text { - Climate Variables }\end{array}$ \\
\hline $\begin{array}{l}\text { WITCH [52] } \\
\text { World Induced Technical Change Hybrid } \\
\text { IAM designed to assess climate change } \\
\text { mitigation and adaptation policies. }\end{array}$ & $\begin{array}{l}\text { - Policy } \\
\text { - Environment } \\
\text { - Energy } \\
\text { - Land Use } \\
\text { - Economy }\end{array}$ & $\begin{array}{l}2005 \text { to } \\
2100\end{array}$ & $\begin{array}{l}\text { - Optimal Climate Change } \\
\text { Mitigation \& Adaptation }\end{array}$ & $\begin{array}{l}\text { - } \text { Biomass } \\
\text { - } \text { Forestry } \\
\text { - Wastes } \\
\text { - } \text { BECCS \& CCS }\end{array}$ & $\begin{array}{l}\text { - } \text { Bio-economy \& Trade } \\
\text { Emissions \& GHGs } \\
\text { - Ecosystems \& Biodiversity } \\
\text { - Land Use }\end{array}$ & $\begin{array}{l}\text { - Policy Design } \\
\text { - Economic Dynamics. } \\
\text { - People \& Welfare } \\
\text { - Energy Sector Characteristics } \\
\text { - Energy Resources }\end{array}$ \\
\hline
\end{tabular}

${ }^{1}$ Derived from analysis using the Bioenergy Literature Database developed presented in this paper. 


\subsection{The Role of Scenarios within Energy Modelling Analyses}

The development and analysis of scenarios within energy models has historically taken place with the objective of informing strategic decisions, such as to test and improve the robustness of strategies before they are implemented, to foresee opportunities to shape future events or to improve the understanding between multiple variables and to identify a mutually desirable paths. Typical outputs from energy modelling scenario analyses include [60]:

- Trend Based Studies where scenarios are developed around multiple combinations of broad and extrapolated trends that provide results ranges that can present both core and error margin trajectories.

- Feasibility Studies are often based around scenarios and present different potential pathways for achieving end-point targets, each with varying levels of pathway performance.

- Modelling Studies tend to present the full outputs of multiple scenario modelling runs, again each highlighting the full range of different potential pathways of working towards an endpoint target.

Over recent years most energy scenarios typically focus on the 'pillars of the energy trilemma' environmental performance, energy security (supply \& demands) and affordability. With the true design of scenarios being to highlight the cheapest option for providing energy that meets the minimum requirements of climate and energy security policy targets [61].

This same approach applies to many leading bioenergy scenarios analyses that have historically been used to highlight the levels of performance of bioenergy systems compared to alternative renewable or fossil fuel technologies. However there is growing consensus that due to the intrinsic relationship bioenergy feedstocks and wide ranging human and natural systems, there is the need to develop models and scenarios that analyse the unseen performance, impacts and benefits of bioenergy systems. For example incorporating ecosystem service benefits [62], sustainability indicators and constraints [33], societal influences [63] and impacts and benefits to agricultural systems [64].

\section{Results}

\subsection{Geopolitical \& Policy Backdrop to Bioenergy Research 2000 - 2018}




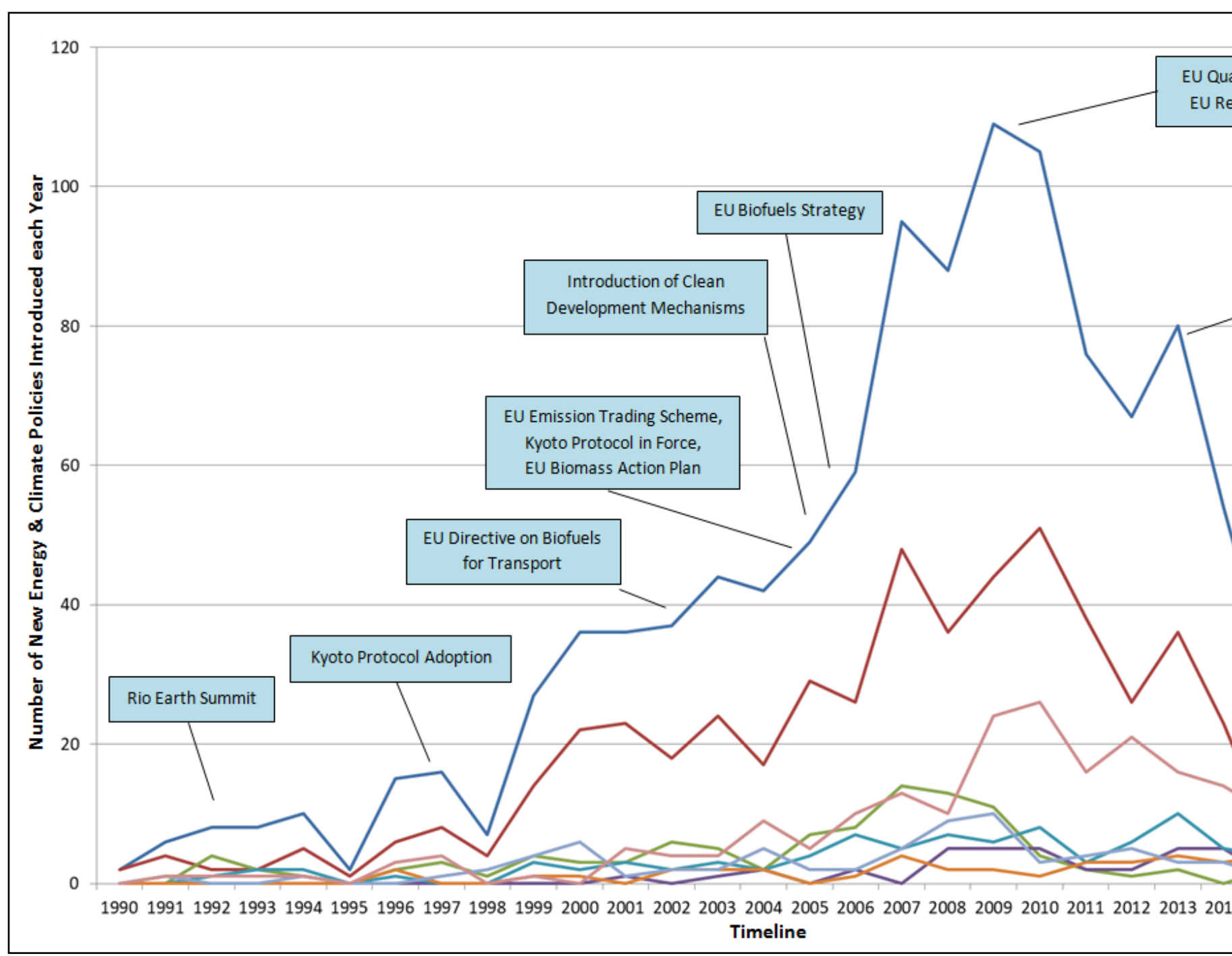

Figure 2 provides a timeline that tallies the number of new energy policy interventions that have been introduced in each global region annually from 1990 to 2018, with annotations highlighting the key 


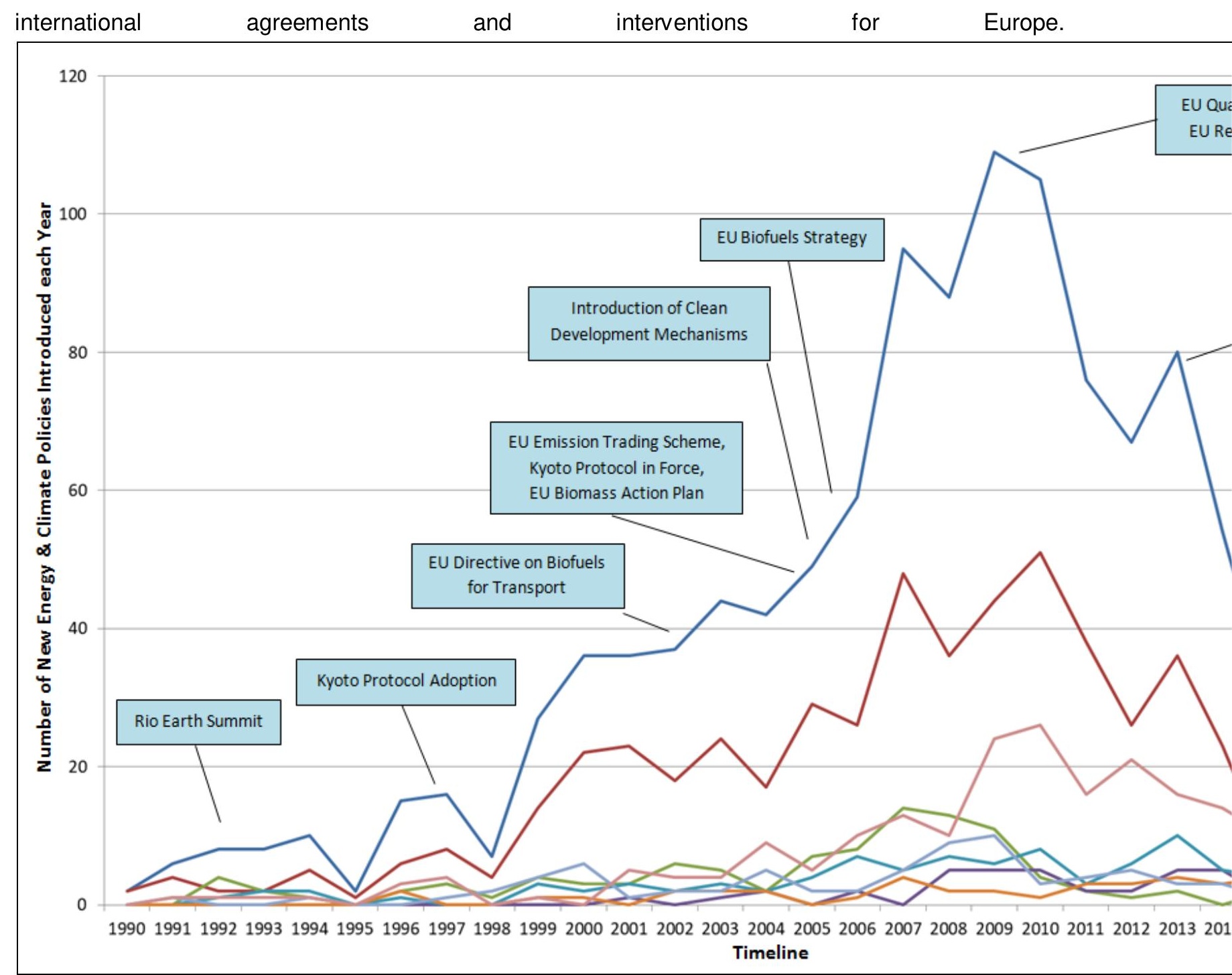

Figure 2 is presented at the start of this paper's Results section as it provides an overview of the policy landscape that provided the backdrop to all recent energy and bioenergy research. For energy policies to be successful they need to be effective in stimulating change, they need to achieve this amidst the complexity of existing energy systems and policy landscapes, but they also need to limit 


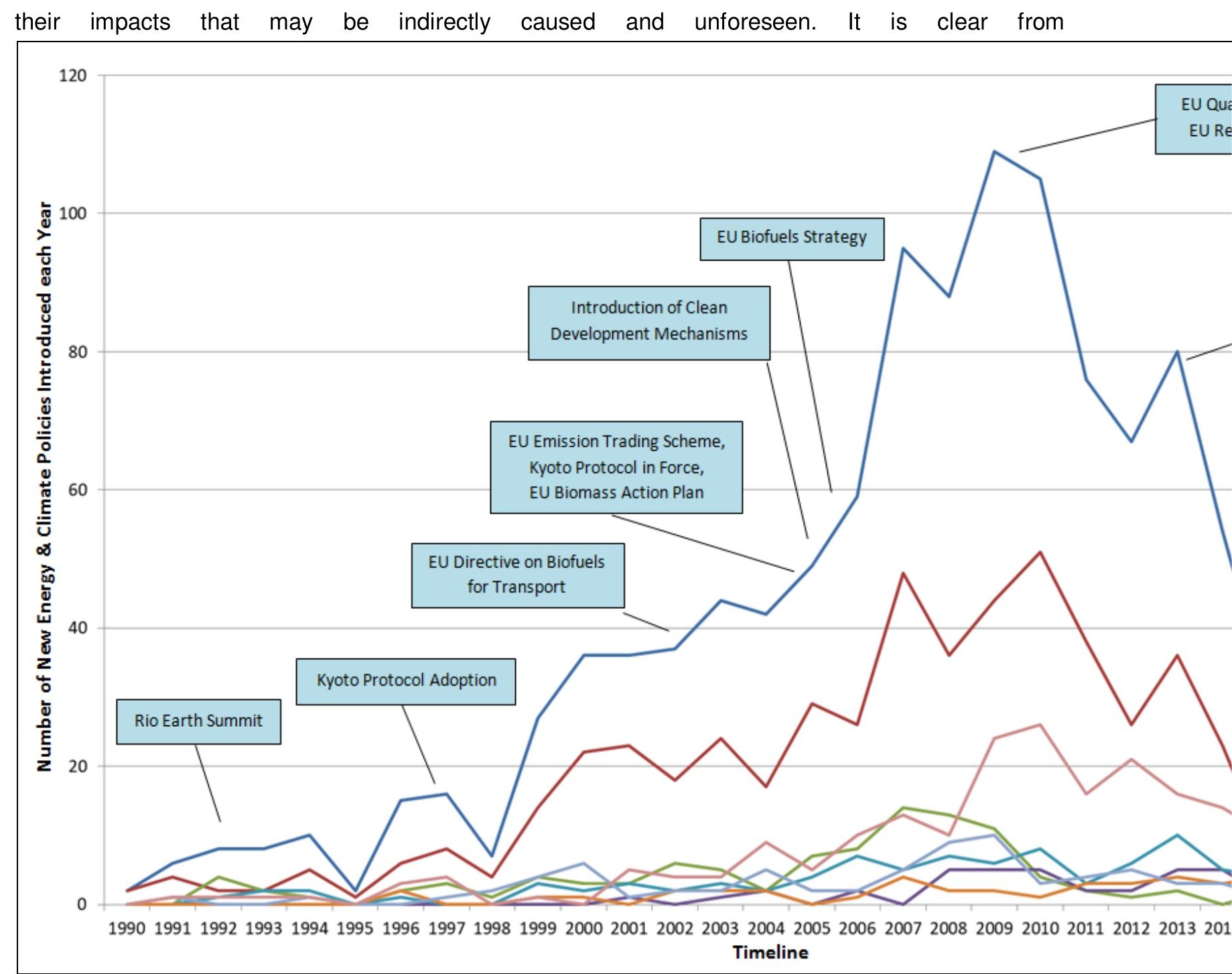

Figure 2 that the policy landscape has been highly congested, each individual policy intervention designed to influence the energy sector in some way. Therefore energy has represented a highly dynamic sector for research focus, with publications over this timeline having to both adapt to and inform many of these interventions. 


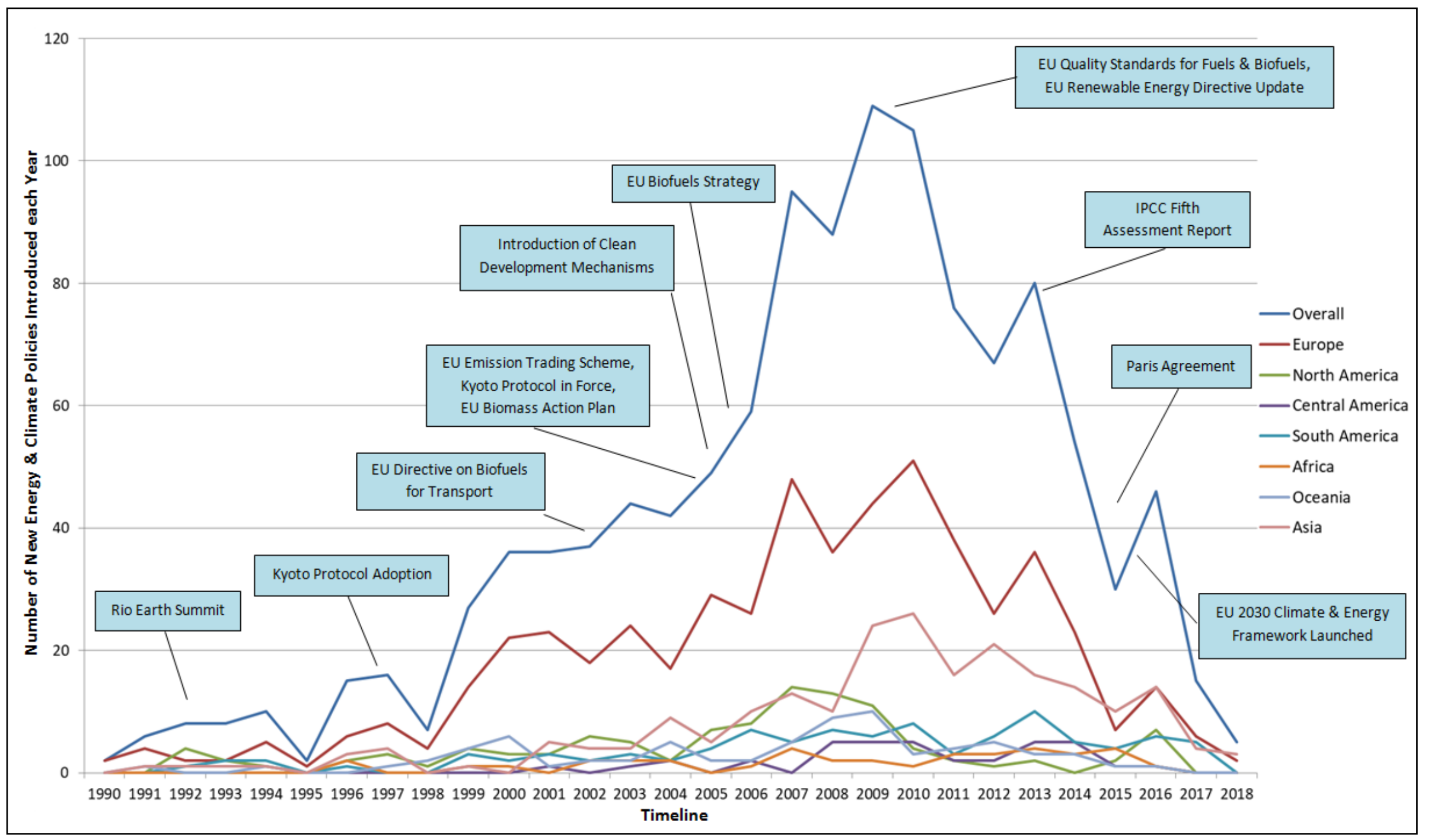

Figure 2: Timeline Mapping Number of New Energy \& Climate Policies Introduced, and Key Interventions from a European Perspective (policies tallied from the IRENA Country Profiles Database [65]) 


\subsection{Profile of Bioenergy Research 2000 - 2018}

The profile of bioenergy research papers published over the analysis timeframe are summarised by Figure 3 and Figure 4. These present data derived from the BLD as listed in Supplementary Table 2 \& Supplementary Table 3. Figure 3 shows that since 2000 there has been an exponential increase in the annual number of papers published, with the greater proportion of the papers analysed focusing on themes of biomass research rather than bioenergy specifically. Of the papers analysed within the BLD, on average $35.4 \%$ of papers apply some form of modelling analysis (max year $47.1 \%$, min year $24.0 \%$ ). Whilst only $0.3-0.5 \%$ of research papers use one or more of the key named models (listed in Table 1 ) covered in this research. Thus Figure 3 highlights that modelling analyses is widely used in biomass and bioenergy research, but the vast majority use varying modelling approaches with bespoke/ unnamed models rather than the higher profile named models.

The total number of published papers each year that cover different biomass and bioenergy issues are summarised in Figure 4. This graph is designed so that a paper covering a specific feedstock and a technology is represented in both the corresponding trend lines for these themes. Figure 4 highlights that coverage of Bioenergy Systems Issues such as water, land use or GHGs is the focus of the greatest proportion of published research. This is followed by coverage of specific Bioenergy Feedstocks, Processes \& Technologies and then Bioenergy Vectors.

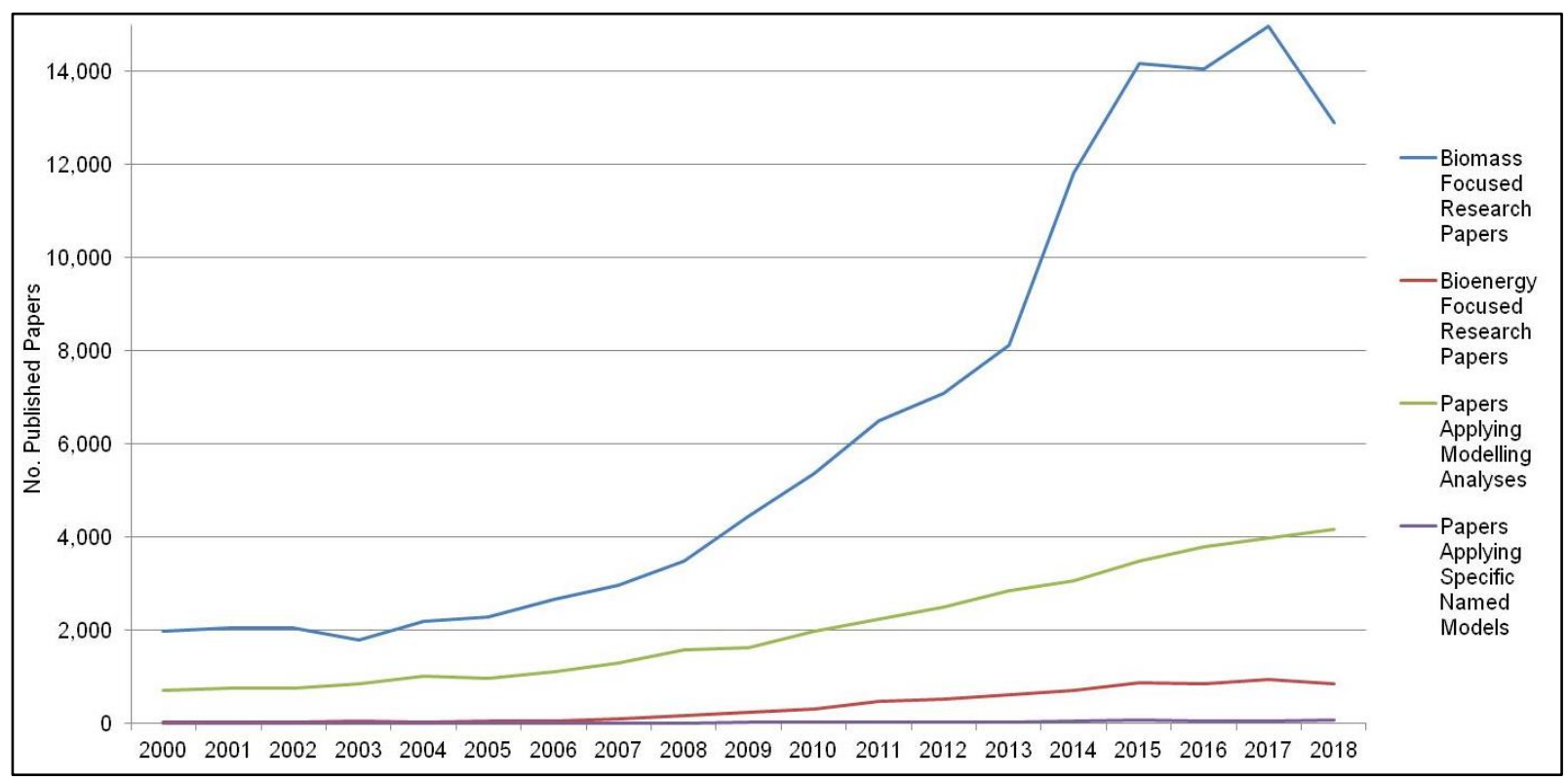

Figure 3: Total Number of Bioenergy Research Paper Published each Year

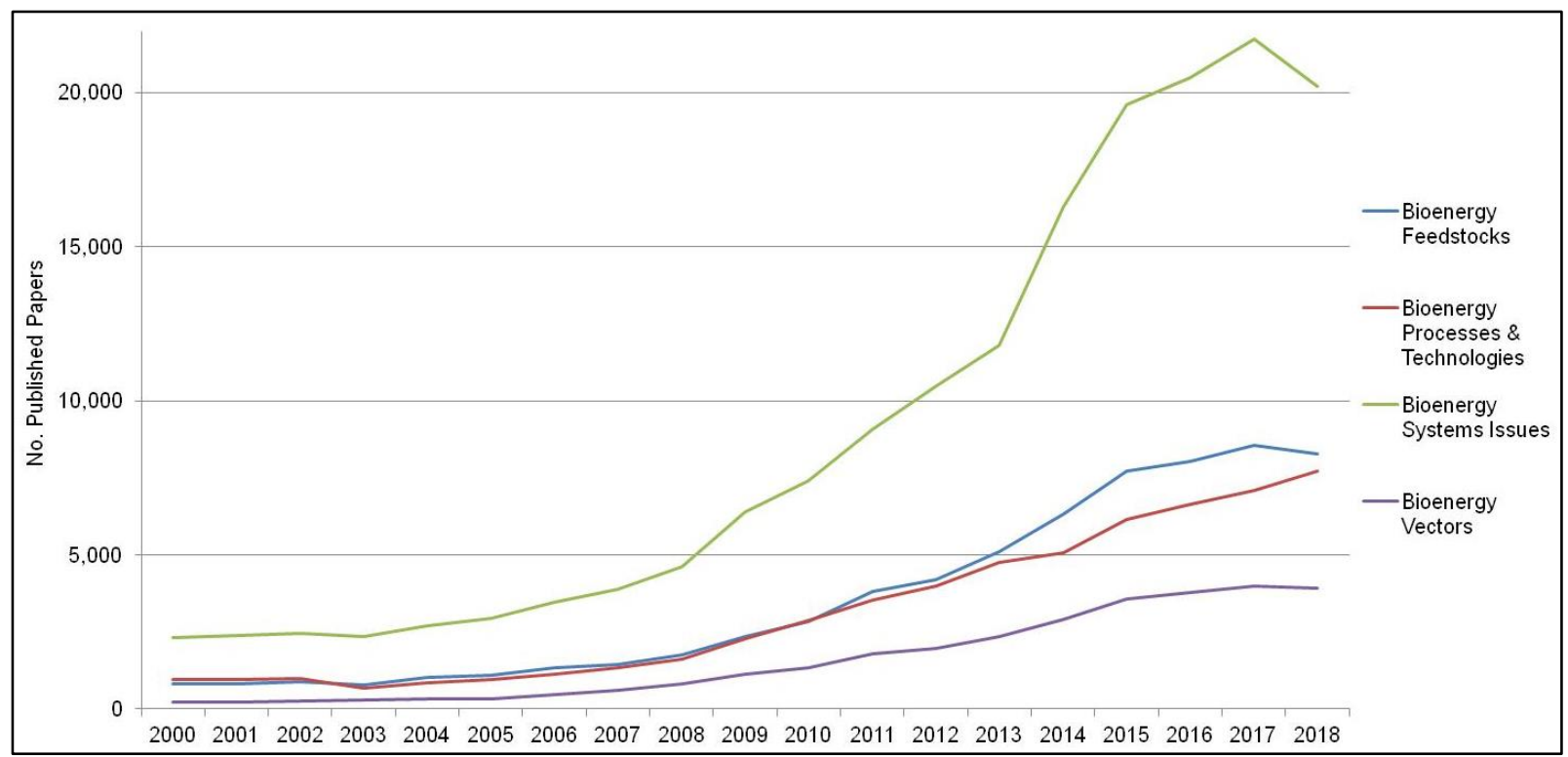

Figure 4: Published Papers each Year Focusing Different Themes of Bioenergy Research

\subsection{Application of Models within Bioenergy Research Papers Published $2000-2018$}


The analyses presented within Figure 5 and Figure 6 provides insights into how different types of models are used within bioenergy research. These figures represent the data derived from the BLD as listed in Supplementary Table 4. Figure 5 presents data relevant to the specific models listed within Table 1, whereas Figure 6 presents data reflecting all publications where any form of modelling analyses are applied. As a result the overall number of papers documented in Figure 6 is larger reflecting the greater extent that bespoke and unnamed models are used in research.

Figure 5 is a stacked line graph that presents the total number of bioenergy research papers published each year that reference use of the specific models (Table 1) analysed within this research. In the year $200025.0 \%$ of these papers referenced one or more of the IAMs, then over the timeframe there is a gradual rise in the number and proportion of papers referencing the IAMs. There is steady use of Energy System Models over the timeline, whilst use of Specialist Models is shown to grow steadily as a proportion of overall modelling papers, with a peak of $66.7 \%$ (in 2006) of modelling papers using one or more of the specific specialist models over the timeline.

A breakdown of the types of modelling approaches used within research is provided by Figure 6 , where the stacked bar charts highlight the use of different modelling approaches over the timeline. Figure 6 shows that use of geographic information system (GIS) and life cycle assessment (LCA) modelling approaches and to a lesser extent techno-economic assessment (TEA) and process modelling are widely used within bioenergy research. There is a relative parity in the use of bottom-up vs. top-down approaches, and reference to energy system models is several times greater than references to IAMs.

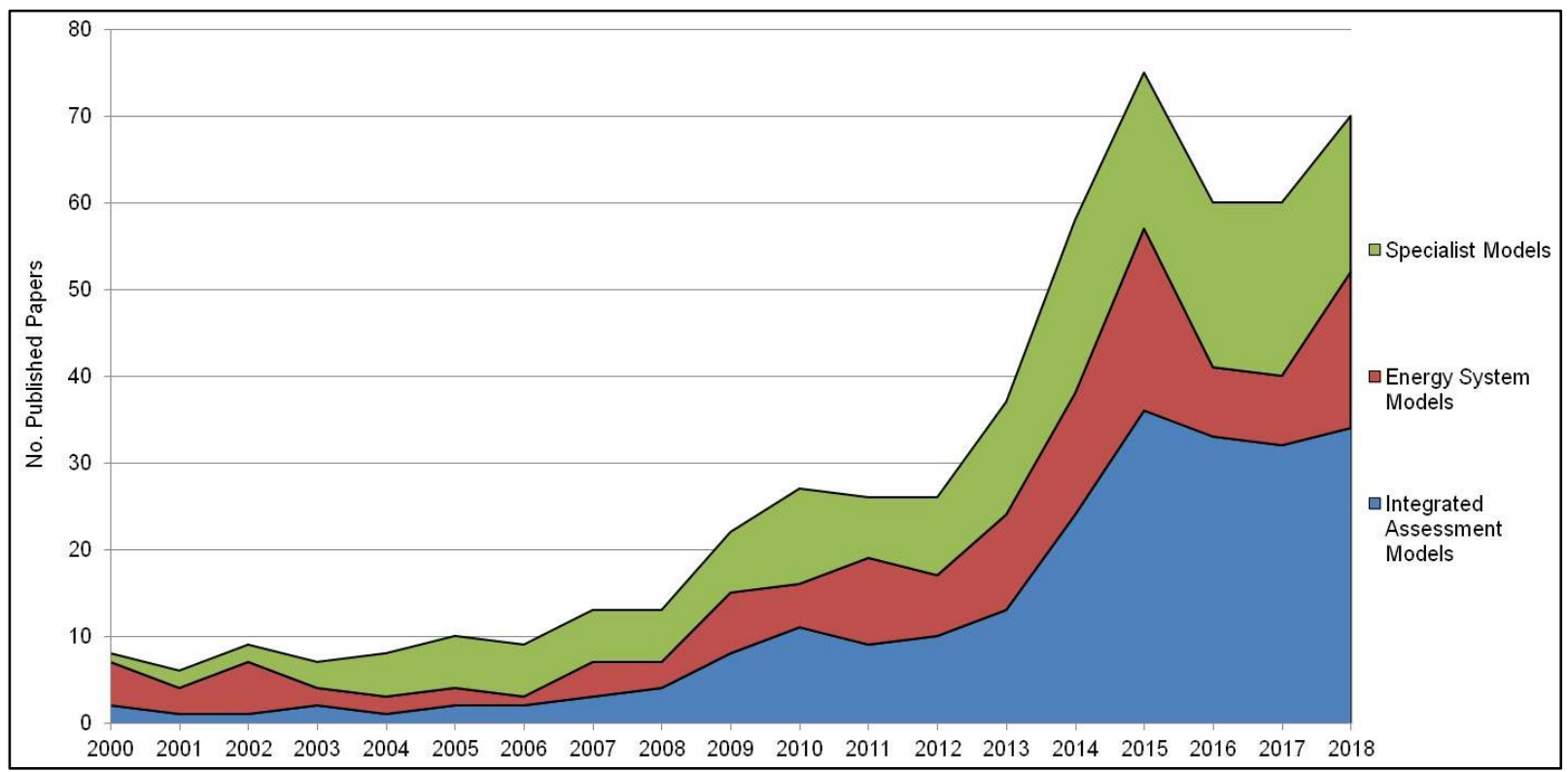

Figure 5: Published Bioenergy Papers each Year that Applied Different Categories of Models

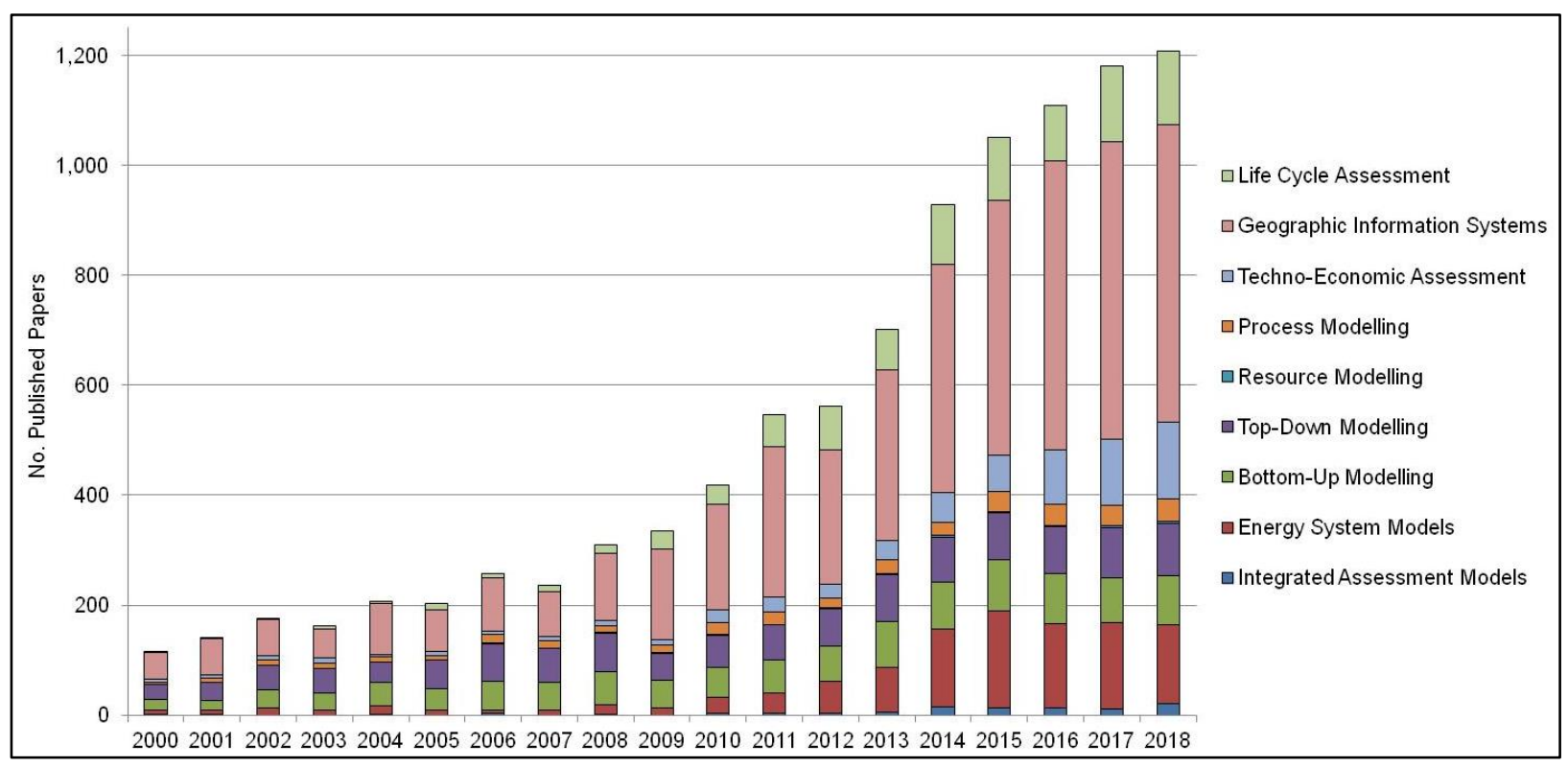

Figure 6: Application of Different Modelling Approaches within Published Bioenergy Papers 


\subsection{Coverage \& Analysis of Bioenergy Research Themes within Different Models}

Based on the assumption that if specific models and modelling approaches are referenced in literature alongside different bioenergy issues, the models are likely being used to analyse that issue; the radar graphs within Figure 7 has been designed to provide analysis of the extent that the different categories of models have been used within research to analyse key bioenergy themes. These present data derived from the BLD as also listed in Supplementary Table 6-9.

There are three different results lines presented within each radar graph, highlighting the coverage of bioenergy issues by the specific named 'IAM's', 'Energy System Models' and 'Specialised Models' (Table 1) included in the BLD. Each of the Figure 7 radar graphs are supported by analyses within 
Table 5 that is designed to provide a clear visual summary of the data derived from the BLD, documenting the extent that different biomass and bioenergy themes are covered by the different categories of models. 
Table 5 clearly highlighting degrees of coverage of different issues by models, ranging from no coverage at all by certain models, to coverage where over $20 \%$ of published papers that apply a modelling approach also focus on a given bioenergy theme.

Radar graph A within Figure 7 documents the coverage of key Bioenergy Feedstocks within research papers using different types of models. This analysis demonstrates that Forestry and Wood are the only feedstock groups covered across all the modelling categories. Energy Crops and Wastes are well represented within IAMs, whereas Energy System Models provide much coverage of Residues and Wastes. Specialised Models cover most of the core feedstocks.

Coverage of Bioenergy Systems Issues is documented in radar graph B, where there are similar trends for each of the model categories. A key highlight from this graph is identifying the bioenergy issues not covered by many of the models. All the model categories document good coverage of issues such as Land Use, Bio-Economy, Emissions \& GHGs, Climate Change and Sustainability. IAMs lack dedicated coverage of issues related to Yield \& Productivity compared to the other model categories. Ecosystems \& Biodiversity are only covered by the Specialised and General Modelling papers. There is distinct lack of coverage of issues such as Jobs, Training \& Skills, ILUC (indirect land-use change), Water, Deforestation and Forestation from all categories of model.

Radar graph C presents the analyses for coverage of Bioenergy Vectors, clearly highlighting that BioPower and Transport Biofuels are the bioenergy vectors that receive the greatest focus and coverage modelling research, with each category of model being used within research to analyse these. This includes biofuels produced for the range of transport modes, shipping, aviation, haulage etc. There is also coverage of Ecosystem Services by each category of model and for Bio-Chemicals in each category apart from the IAMs. A key highlight from radar graph $C$ is the lack of coverage of certain bioenergy vectors by many/ all of the modelling categories, especially for Bio-Heat.

The analysis for Bioenergy Processes and Technologies within radar graph $\mathrm{C}$ highlights some clear contrasts in coverage between the models. The IAM radar graphs highlight extremely strong coverage of BECCS (bioenergy with carbon capture and storage) \& CCS (carbon capture and storage) technologies, with comparatively little or no coverage of other technologies. The Energy System Models radar graph has broader coverage of many issues including Pyrolysis, Gasification and Catalysis. Within the Specialised Model graph there is a clear spike in coverage of Bio-Chemicals and Fermentation, more so than for each of the other model categories. There is also uniform coverage of 'Drying' across the graphs, perhaps highlighting the importance of this processing step within a large number of bioenergy systems.

The outputs of this analysis may be used to verify where the different types of models are/ can be used to analyse bioenergy issues. However when interpreting these results it is important to recognise the different scopes and purposes of these models and the resulting limitations. For example as IAM's are designed to undertake global long term analyses with endogenous energy, land and agricultural system representation, it is not surprising they are not used explicitly to analyse issues related to bioenergy jobs and skills. It is also important to also highlight that just because a specific bioenergy issues is not referenced in the literature alongside models, it does not mean the model is not capable of covering that issue. For example within the results for the IAMs, no coverage of $1^{\text {st }}$ generation biofuels or briquette feedstocks - this may be due to these feedstocks either being identified as being not competitive in the long term ( $1^{\text {st }}$ generation biofuels), or aggregated under their end uses (briquettes). 
A. Coverage of Bioenergy Feedstocks

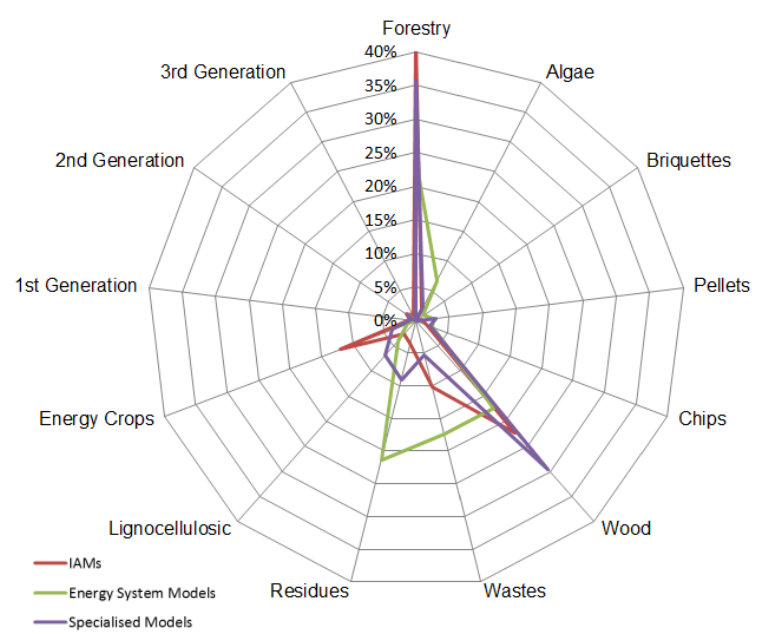

C. Coverage of Bioenergy Vectors

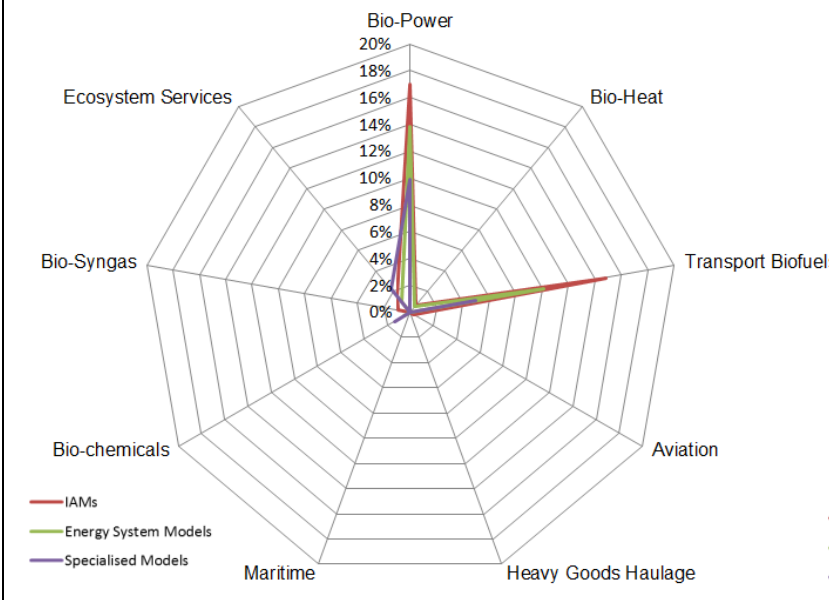

B. Coverage of Bioenergy Systems Issues

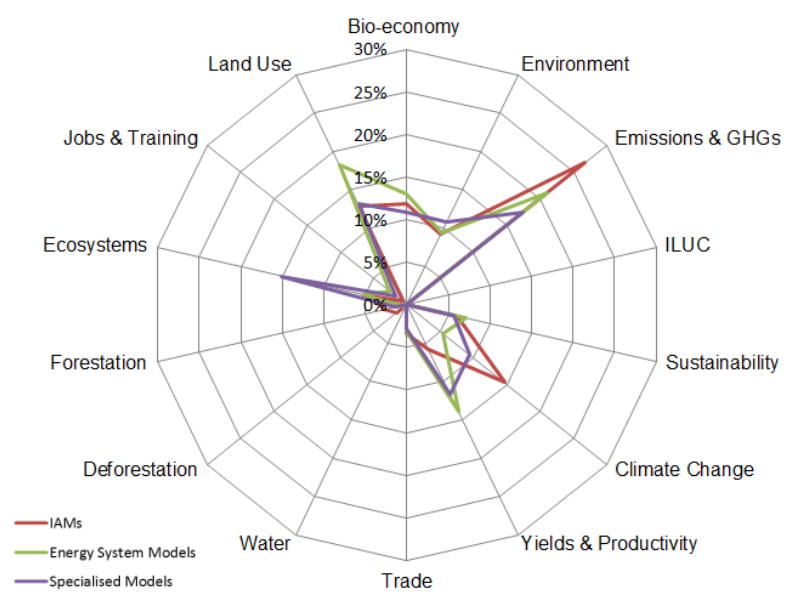

D. Coverage of Bioenergy Technologies \& Processes

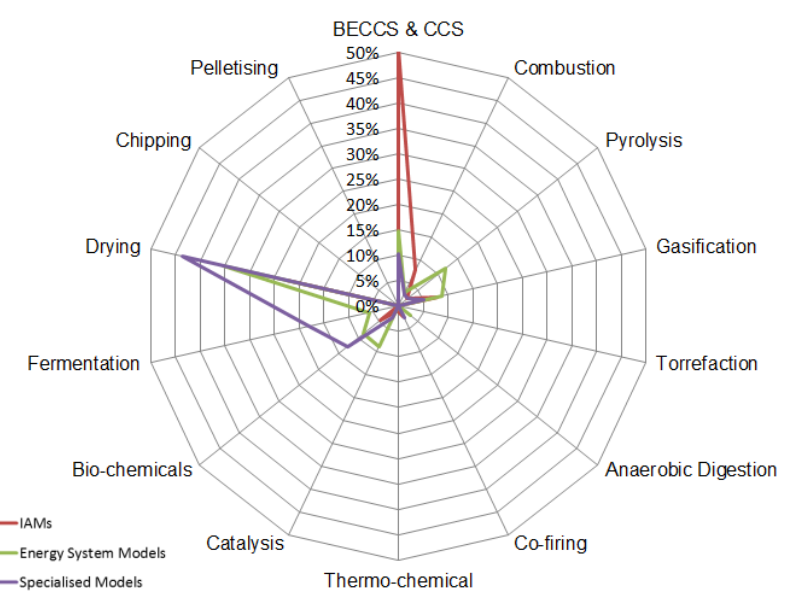

Figure 7: Radar Graphs Highlighting the Extent that Key Bioenergy Issues are Covered by Bioenergy Modelling Research - the percentages reflecting the proportion of the overall number of bioenergy modelling research papers that focus on each bioenergy research theme. 
Table 5: Coverage of Key Bioenergy Issues by Different Categories of Models, Evidenced by Publications 2000 to 2018

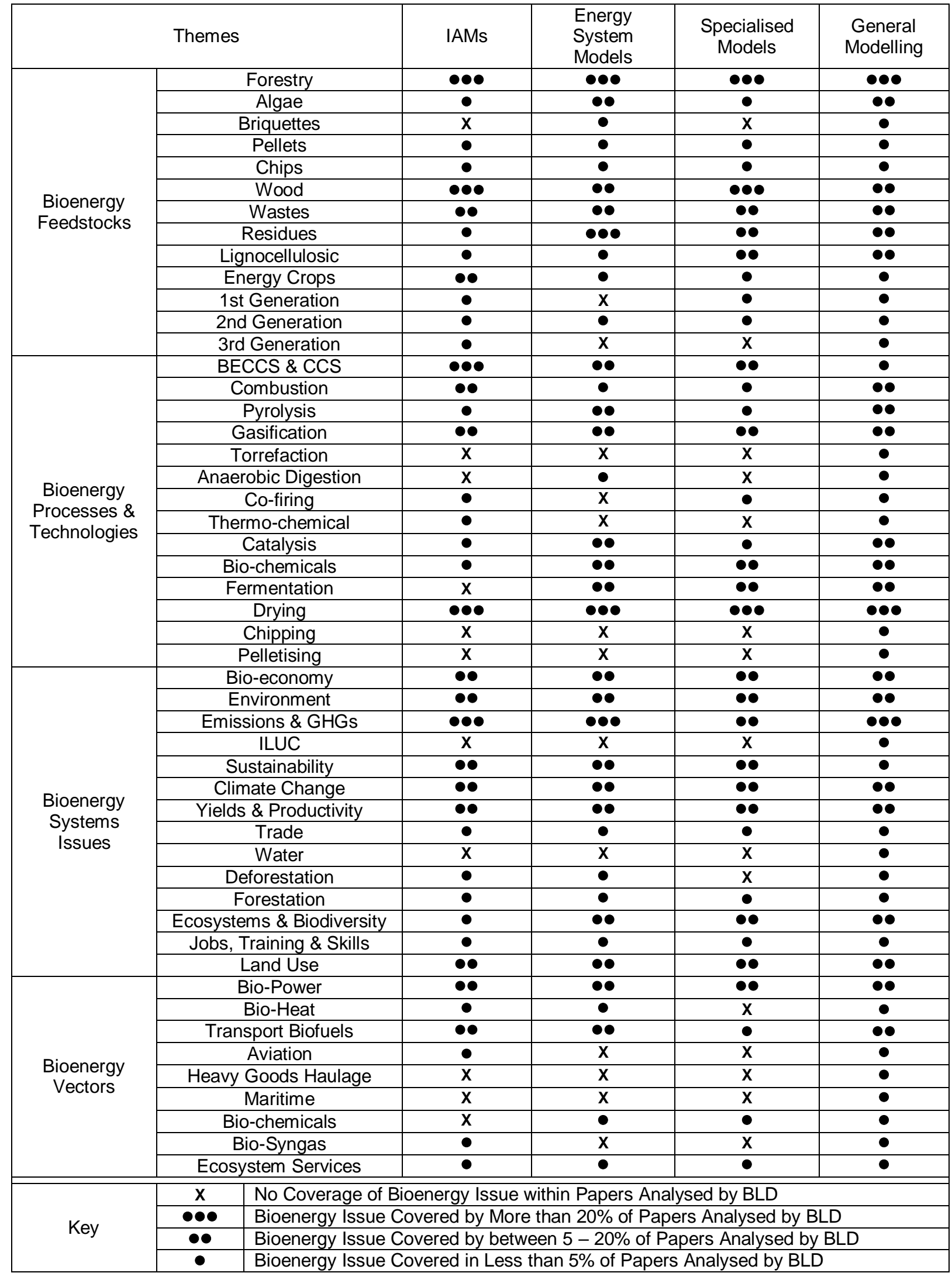




\section{Discussion}

\subsection{Biomass \& Bioenergy Research Papers Published 2000 - 2018}

This research highlights an exponential rise in the number of research papers focusing on biomass and bioenergy that have been published since 2000. This is not surprising given the rise in importance of climate change as the leading environmental challenge and renewable energy technologies such as bioenergy being one of the prominent mechanisms pursued to curb emissions. With renewables growing in importance for Government's, policy interventions and research funding has followed - countries dedicating the greatest funds for research are those that also produce the most renewable energy research papers - USA, followed by China, the UK and then Germany [66].

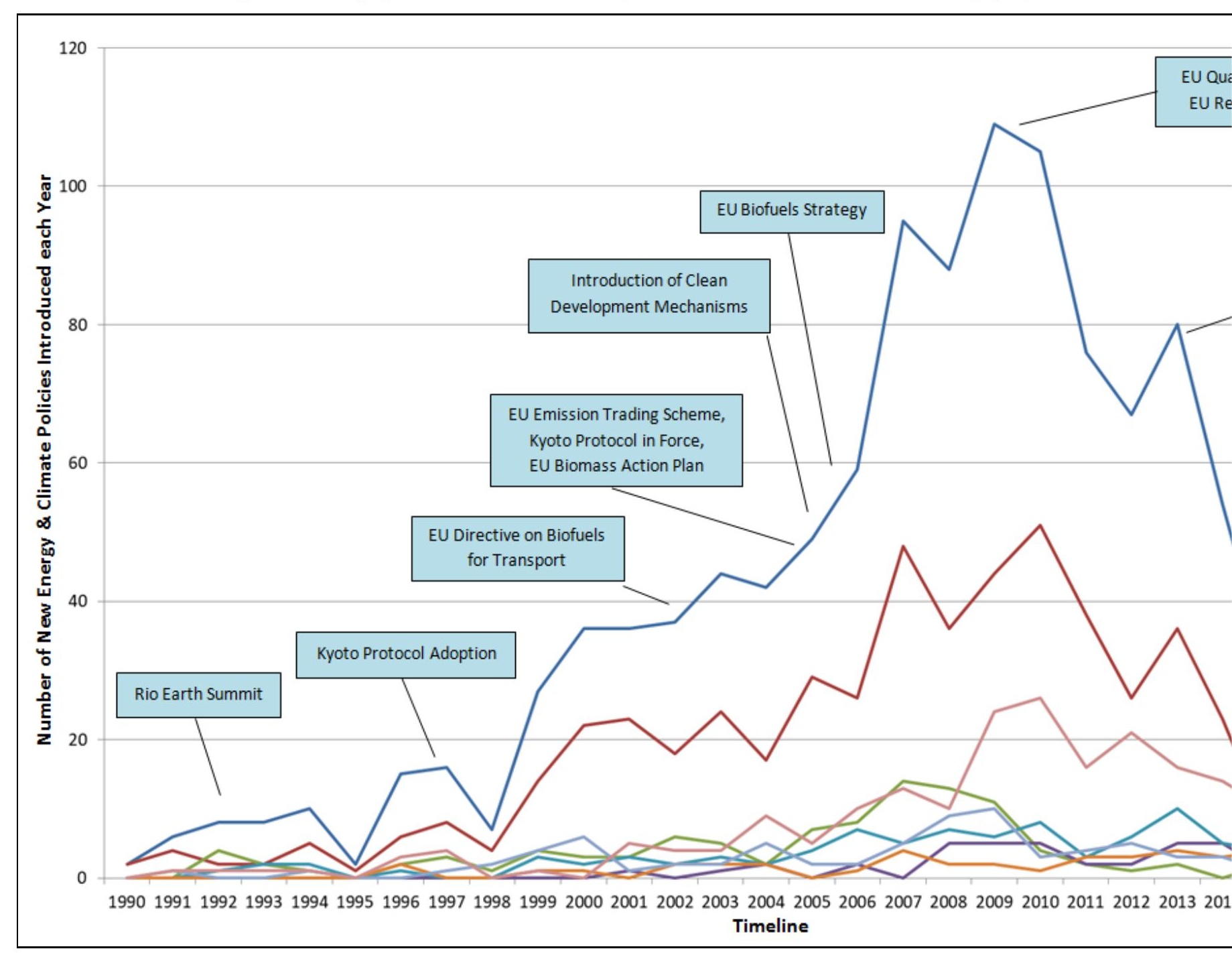

Figure 2 demonstrated there has also been an exponential increase in the number of policy interventions, each being developed through and influencing further research activity. Nachmany \& Setzer (2018) [67] accounted 1,500 individual global climate policies/ legislations in 2017, rising from just 72 in 1997. As renewable energy research themes have matured, an increasing number of new themes have also emerged and grown in prominence. This pattern is reflected within the analyses of this research, where climate change and emissions issues particularly have received increasing focus within the literature and has been the subject of the different categories of models. With the diversification of research themes covered, there has also been a widening of the scientific disciplines engaging with the topic, Alcayde et al (2018) [68] finding increased contributions from scientists not traditionally widely associated with energy research such as economists, social scientists and biological scientists. 
Many of the graphs presented in this paper also demonstrate an interesting feature of biomass and bioenergy research, where there is a clear increase in the rate of publications from 2013 onward. There could be many reasons for this; we suggest this may a direct feedback linked to the increase in levels of bioenergy research taking place leading and the increased level of scrutiny bioenergy was receiving. Reports were published such as the joint NGO 'Dirtier than Coal' [69] , and the Searchinger \& Heimlich's 'Avoiding Bioenergy Competition for Food Crops and Land' [70] that questioned the sustainability and GHG performance of large scale bioenergy - these fuelling further research interest and much work by the bioenergy research community and beyond to test the concept of bioenergy being a sustainable low carbon energy option. Beyond 2013 the analysis shows that annual number of bioenergy papers published plateaus and then the rate falls back. This could represent a decline in the interest in bioenergy studies caused by a movement away from bioenergy research, as many of the key questions raised by the aforementioned Reports are answered by the increased research focus on bioenergy.

\subsection{Performance of Different Categories of Models \& their Coverage of Key Bioenergy Issues}

Models are developed for many reasons and are often adapted and evolve to analyse research questions that may originally have never been foreseen when the models was first designed. Models are also always simplifications of reality for the sake of analysis and as a consequence there will always be models which don't adequately cover certain issues or features, or don't cover certain elements at all [13]. Therefore there should always be a degree of caution when interpreting outputs from modelling tools and this is doubly important when models are used as tools to inform policy.

The literature reviewed and analyses presented in this paper has demonstrated the strengths and weakness of different types of bioenergy models in covering bioenergy issues through highlighting the extent that key models are used in published research. Based on our analysis and supporting literature [24], Table 6 has been produced to provide an overview of the capability, performances, strengths and weaknesses of IAMs, Energy System Models and Specialist Models when used in bioenergy research.

Each of the model types can be very successful at answering bioenergy questions that are compatible with the design and framework of assumption intrinsic to each. Problems, uncertainties and risks for policy occur when models are used out of context or elements and unforeseen impacts are not covered by the model are subsequently overlooked. Therefore key findings from this research are highlighting the bioenergy research themes that different models do not/ cannot cover. This represents a risk to bioenergy decision making processes based on the outputs of these models as they may not allow consideration of many wider issues. For example our research shows in 
Table 5 that IAMs have strong coverage of wood and forestry based feedstocks, environmental and emissions themes and technologies such as BECCS - although this doesn't mean that IAMs cover these bioenergy themes as well as could be achieved by other modelling approaches. Outside of these, IAMs do not/ cannot capture the many other issues associated with sustainable bioenergy systems and the nuances between them. Energy System Models have been shown to have better coverage of the different bioenergy processes and technologies and of different types of bioenergy feedstocks. Whilst the research finds that there are Specialists Models that have been developed that offer bespoke analysis approaches covering all the different research themes associated with bioenergy.

Relying on a single category of model or just one specific model will likely only provide outputs that give insight on a limited range of themes. As bioenergy is intrinsically linked to people, processes and land and as such will impact and benefits each, there are many more themes that need consideration compared to other renewable technologies. It is not feasible to develop an all-encompassing bioenergy model that covers all these linkages and captures the nuances between different systems. This therefore leans towards a strong argument for the use of multiple models in parallel each with different approaches in order to build a more robust overall conclusions [71].

\subsubsection{Limitations of Different Modelling Approaches}

The demands placed on models to identify pathways towards decarbonisation whilst balancing environmental, societal, economic and technological constrains has led to the development of models with increasing degrees of complexity. Taking account of the many variables that underpin this complexity and the need to assign assumptions to each is a key reason why different models can generate broad ranging outputs across their scenarios. With so many models now producing outputs that provide multiple answers to questions, it is clear why the ability of models to generate feasible long term forecasts is increasingly being regarded with degrees of scepticism [72].

Schinko et al. (2017) [73] identify that for the majority of energy models, their drivers are heavily reliant on exogenous input assumptions - those determined outside of the model such as external targets and behaviours etc. These in turn drive the endogenous factors within the models - factors such as price shifts due to functional relationships between the variables that have been built within the model. It is therefore important to acknowledge and highlight the limitations and the potential for errors that may stem from the way models are designed. For example all models can only forecast within the dynamics of the designed relationships between the model's assumptions and variables, they are overwhelmingly not equipped to analyse radical changes such as breakthroughs in technological development. Although it is radical changes such as the emergence of new technologies that will potentially play a large part in transformations towards low carbon futures.

Table 6 lists some of the limitations inherent to the different categories of models and the analyses approaches covered in this paper. These limitations are largely a result of the design of the models, for example [73]:

- There is a cost to the top down approach of IAMs and their aims to include as many factors as possible (economy, climate, society, environment) and to analyse the feedback between these. To capture all these interactions IAMs operate on coarse levels of detail and assumptions that ultimately filter through to the outputs generated. For example IAMs will likely only have limited representation of alternative technologies so the outputs are restricted to the assumptions around these. This can also lead to problems where IAMs share data files with wider models (soft-linked), achieving convergence and consistency between the models can be problematic stemming from the use of coarse values for the assumptions built within the IAM.

- $\quad$ CGE and PE based models have limitations that stem from the design and approaches built within the model architecture. These models are driven by key assumptions such as price changes, and are designed to have specific coverage of sectors of economic activity, therefore any wider outputs need to be analysed bearing in mind the focused scope of these models. For example PE models are only able to capture the techno-economic aspects of a system reflective of the sectors included in the model, therefore cannot be used to analyse any wider interactions relating to environmental or social systems that may result from the deployment of different technologies.

- Specialist models that apply a bottom-up analysis approach to focus on a specific question are capable of capturing rich technological, environmental, economic and social details, and 
through this can identify both attractive and inferior potential solutions. The limitations to this approach stem from the complexities required - relevance of outputs will be limited to the focused system boundaries of the questions being analysed, and there can be high computation requirements to achieve these. The high focus of this approach may also result in the non-coverage of macro-systems and feedbacks, leading to optimal solution identified by specialist models potentially not taking into account wider real-life systems. 
Table 6: Summary of the Capability \& Characteristics of Different Categories of Models

\begin{tabular}{|c|c|c|c|c|}
\hline & \multirow{2}{*}{$\begin{array}{l}\text { Integrated Assessment Models } \\
\text { (IAM) }\end{array}$} & \multicolumn{2}{|c|}{ Energy System Models } & \multirow[b]{2}{*}{ Specialist 'Bottom-Up' Models } \\
\hline & & $\begin{array}{l}\text { Computable General Equilibrium } \\
\text { (CGE) }\end{array}$ & Partial Equilibrium (PE) & \\
\hline Application & $\begin{array}{l}\text { - Bioenergy resource potentials based on } \\
\text { varying assumptions \& criteria } \\
\text { - Contribution to long term climate policy } \\
\text { - Impacts of bioenergy policies on global } \\
\text { land use, water and biodiversity }\end{array}$ & $\begin{array}{l}\text { - Economic impacts of biomass \& } \\
\text { bioenergy policies } \\
\text { - Policy Effects such as resulting GHG } \\
\text { emissions }\end{array}$ & $\begin{array}{l}\text { - Indirect substitutions such as land use \& } \\
\text { rebound effects on multiple sectors } \\
\text { - Sector impacts of bioenergy policies on } \\
\text { agriculture, forestry, land use change, } \\
\text { energy system \& GHG emissions }\end{array}$ & $\begin{array}{l}\text { - All technical aspects of feedstock } \\
\text { supply, conversion \& use. } \\
\text { - Validation of other studies with } \\
\text { broader scopes. }\end{array}$ \\
\hline Timeframe & - Long & - Short to Medium & - Short to Long & - Short to Long \\
\hline $\begin{array}{l}\text { Strength of } \\
\text { Approach }\end{array}$ & $\begin{array}{l}\text { - Integrating different systems in one } \\
\text { modelling framework } \\
\text { - Potential for analysing feedbacks } \\
\text { between human \& natural systems, } \\
\text { trade-offs \& synergies with political } \\
\text { strategies } \\
\text { - Developed around long term dynamics }\end{array}$ & $\begin{array}{l}\text { - Comprehensive coverage of economic } \\
\text { sectors \& regions to account for inter- } \\
\text { linkages } \\
\text { - Explicit modelling of limited economic } \\
\text { resources } \\
\text { - Measuring economy-wide \& global } \\
\text { effects of bioenergy policies }\end{array}$ & $\begin{array}{l}\text { - Detailed coverage of interest sectors } \\
\text { with full market representation } \\
\text { - Explicit representation of biophysical } \\
\text { flows \& prices }\end{array}$ & $\begin{array}{l}\text { - Typically greater detail on regional } \\
\text { aspects, policy measures \& } \\
\text { environmental indicators } \\
\text { - Detailed insights into techno- } \\
\text { economic, environmental \& social } \\
\text { characteristics \& impacts of bio-based } \\
\text { systems }\end{array}$ \\
\hline $\begin{array}{l}\text { Limitations } \\
\text { of Approach }\end{array}$ & $\begin{array}{l}\text { - High level of aggregation of highly } \\
\text { complex systems } \\
\text { - Unsuitable for short term assessments } \\
\text { - Large number of assumptions }\end{array}$ & $\begin{array}{l}\text { - Level of aggregation may mask the } \\
\text { variation in the underlying elements. } \\
\text { - Scope of CGE models necessitates } \\
\text { simplified trends and outputs } \\
\text { - Few or no explicit representation of } \\
\text { quantities for biophysical flows }\end{array}$ & $\begin{array}{l}\text { - Optimisation of agent welfare, but only } \\
\text { the sectors represented in the model } \\
\text { - No consideration of macro-economic } \\
\text { balances \& impacts on non-represented } \\
\text { sectors }\end{array}$ & $\begin{array}{l}\text { - Needs large number of assumptions } \\
\text { for long term projections } \\
\text { - No inclusion of indirect \& induced } \\
\text { effects outside the boundaries of the } \\
\text { study - often deliberately ignoring } \\
\text { interactions with other sectors }\end{array}$ \\
\hline $\begin{array}{l}\text { Strong } \\
\text { Coverage of } \\
\text { Bioenergy } \\
\text { Themes }\end{array}$ & $\begin{array}{l}\text { - Forestry \& Wood Feedstocks } \\
\text { - BECCS \& CCS } \\
\text { - Emissions \& GHGs }\end{array}$ & $\begin{array}{l}\text { - Forestry \& Wood Feedstocks } \\
\text { - Residue Feedstocks }\end{array}$ & - Emissions \& GHGs & $\begin{array}{l}\text { - Forestry \& Wood Feedstocks } \\
\text { - Emissions \& GHGs }\end{array}$ \\
\hline $\begin{array}{l}\text { No } \\
\text { Coverage of } \\
\text { Bioenergy } \\
\text { Themes }\end{array}$ & $\begin{array}{l}\text { - Bioenergy Processes \& Technologies } \\
\text { (other than BECCS + CCS) } \\
\text { - Pre-treatment Processes } \\
\text { - ILUC } \\
\text { - Water Issues } \\
\text { - Bio-chemicals }\end{array}$ & $\begin{array}{l}\text { - ILUC } \\
\text { - Water Issues }\end{array}$ & $\begin{array}{l}\text { - Alternative Transport Biofuels (non- } \\
\text { road) } \\
\text { - Pre-treatment Processes }\end{array}$ & Coverage of all Bioenergy Themes \\
\hline
\end{tabular}




\subsection{Use of Modelling within Bioenergy Research \& Policy Development}

With the outputs of energy models influencing decisions and policy development, it is important that that the methods and approaches of models are scrutinised to ensure that validity of the recommendations they help inform. Policy makers should in theory always use the most appropriate models to address their specific questions, choosing models based on relevant criteria such as the inclusion of different technologies, time horizons, and granularity of expected results. However in reality, bioenergy modelling analyses informing policy is typically completed using a small number of established high profile models that have been developed over a number of years. An example being the core IAMs whose collective outputs form the basis of the Intergovernmental Panel on Climate Change's (IPCC) recommendations for preventing climate change. These large 'incumbent' models are linked to institutional modelling teams who have leading expertise in the specific modelling approaches compatible with 'their' Model, who use the same data sources, who develop their own professional networks and attend the same conferences. These incumbent models retain their status and prevent any significant breakthrough of alternative models by continually adding new analysis modules such as to assess GHGs or land use - this increases the complexity of the models and with it tightens control over the model through ensuring only limited circle of specialists are able to understand and review methods [7].

The development and emergence of new IAMs is also hindered by the level of technical content required to come close to competing with the existing models - each of these having many years of continuous develop by large expert teams. Although there are examples where new modelling teams have tried to break through, for example from Brazil [74] and China [75]. The existing IAM research community have also committed to increase collaboration with bespoke models and to gain detailed process representations in order to improve the representation of issues that IAMs do not cover. This is evidenced by the study by Wicke et al. (2014) [24] which comprises authors from various IAM teams, also Luderer et al. (2019) [76] that demonstrates collaboration work between IAMs and LCA and detailed input-output models.

Although as our research highlights within 
Table 5, although leading named models such as the IAMs provide highly valuable assessment tools, they currently don't and can't capture the whole story of perspective bioenergy systems. Our research with the BLD has demonstrated that use of the prominent named models (list in Table 1) such as those analysed within this research are also only represented in a small minority of the overall body of bioenergy research (Figure 3) - over the past 20 years researchers have moved away from the large inaccessible institution models and are instead increasingly using specialist bespoke tools. These specialist models being developed and applied to focus on the full spectrum of bioenergy research themes ( 
Table 5). This means that there is a great body of bioenergy research currently taking place using bespoke models that won't necessarily have the same established dissemination pathways through to policy decision makers, who continue to use the established models such as the IAMs.

\subsubsection{Do Models Provide the Information Policy Makers Require - A UK Perspective?}

Ideally bioenergy models would provide policy makers with information that allows them to develop policy that promotes sustainable bioenergy taking consideration of the many themes associated with bioenergy pathways. As there is no single model that can currently provide that data covering all these nuances, caution should be applied if decisions are developed from one category or one specific model. For example the UK currently has a complex policy landscape backdrop (

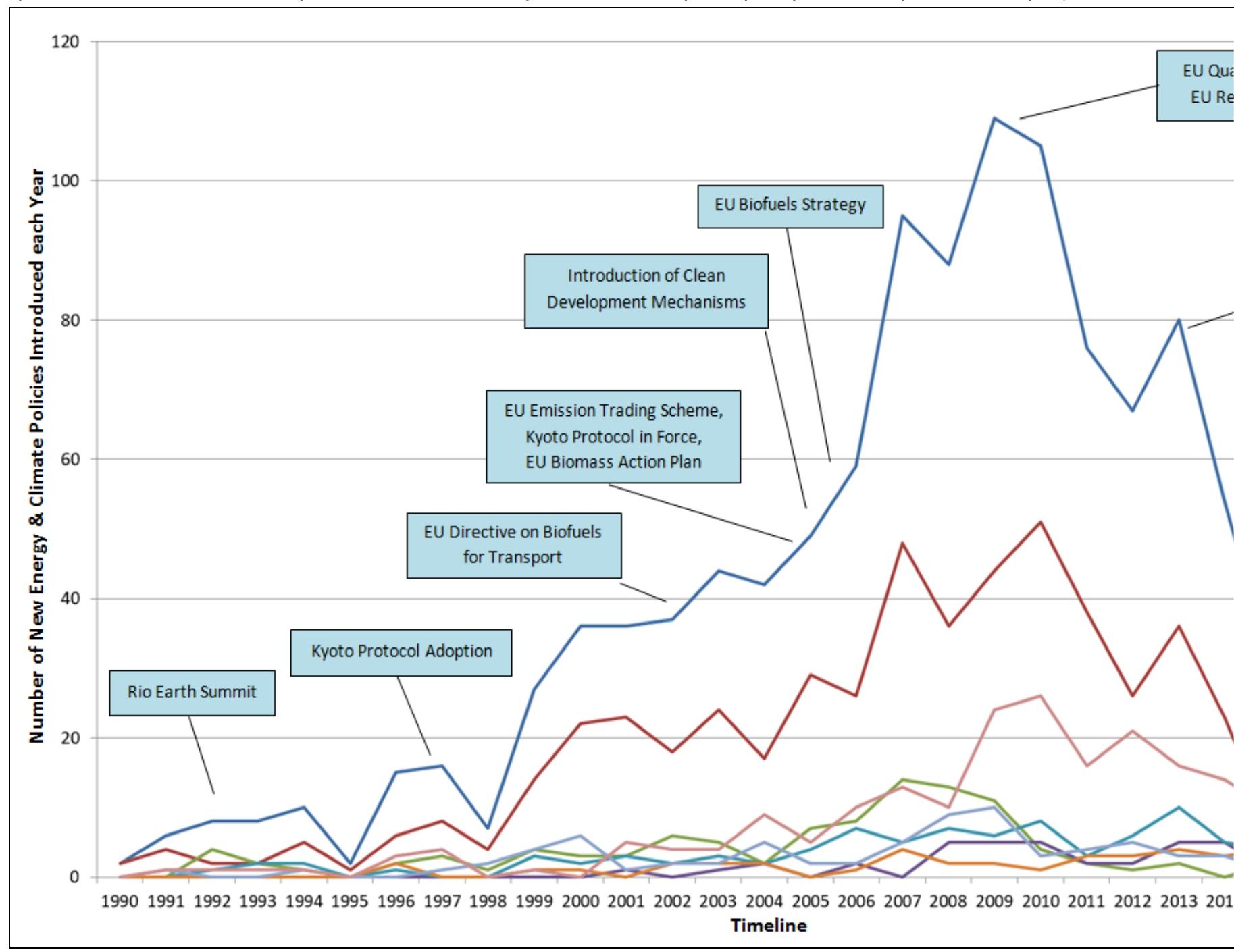

Figure 2) that has step by step evolved to the current status where the UK now has overarching target to become carbon neutral by 2050 [1]. IAMs may provide the best modelling approach to analyse and forecast how bioenergy may fit with wider energy and environmental systems to develop pathways for reducing emissions and achieving its target, whilst Energy System Models may be applied to evaluate different bioenergy technology options. However at a sector level the UK has separate targets for decarbonising heat, power and transport whilst also developing the UK bio-economy and ensuring the bioenergy sector is sustainable and delivers genuine whole lifecycle emissions - our research shows that any given IAM or Energy System Model simply cannot provide outputs that would allow balanced decision making covering all these issues. Complementary specialist models would be required to provide greater focus on specific feedstocks, technologies or systems issues. Our research shows that there are a great many specialist bioenergy models represented within wider literature that cover these issues but simply do not necessarily have clear dissemination pathways through to decisions makers. 


\subsubsection{Key Recommendations for Using Energy Models to Inform Bioenergy Decision Making}

There should always be a degree of caution when interpreting outputs from modelling tools and this is particularly important when models are used as tools to inform decision making. Although to develop energy systems and bioenergy sectors that will be the mechanism that drives the transition towards low carbon economies, it is important that the targets, strategies and roadmaps are designed with the support of the best possible analyses provided by models. It is not feasible to develop an allencompassing bioenergy model that covers all the linkages and captures the nuances between different systems, but there is a strong argument for using multiple models in parallel each with different approaches in order to build a more robust overall conclusions.

This could be achieved through developing a versatile framework of IAMs, Energy System Models and Specialist Models that could be integrated to provide 'modular modelling approach' to utilise the strengths and mitigate for the weaknesses of any given individual model. In practice using the example of the transport sector this could mean: using Specialist Models to identify and evaluate the performance of different alternative fuel/ transport options; using Energy System Model to analyse how these may be integrated with the wider energy systems and infrastructure; and IAMs to evaluate the GHG and wider macro-impacts of these technological interventions.

\section{Conclusions}

The research presented in this paper was undertaken to analyse the role of bioenergy within different categories of energy models, the aim being to evaluate the performance of the different modelling approaches in evaluating the many themes that collectively determine the overall performance of bioenergy systems. The research presented a literature review based assessment of Integrated Assessment Models (IAMs), Energy System Models and Specialist Models, with focus on highlighting the characteristics of each and their strengths and weaknesses in analysing bioenergy research questions. A Bioenergy Literature Database (BLD) was developed to provide a tool to analyse the characteristics of bioenergy research publications over the timeline 2000-2018; to analyse the changing focus and roles of modelling within bioenergy research, and; to identify whether how different categories of models are applied in analysing different key bioenergy research themes.

This research highlights an exponential rise in the number of research papers focusing on biomass and bioenergy, totally 124,285 individual published $2000-2018$. On average $35.4 \%$ of papers published annually applied some form of modelling analyses. The vast majority of these bioenergy modelling papers apply bespoke models rather than notable high profile IAMs or Energy System Models. GIS and LCA modelling approaches and to a lesser extent TEA and Process Modelling are most widely applied modelling approached used within bioenergy research.

Models can be very successful at answering bioenergy questions that are compatible with the design and framework of assumptions intrinsic to each. However models are developed for many reasons and are often adapted or evolve to analyse research questions that may originally have never been foreseen. When applied to analyse bioenergy questions, this research finds that different types of categories of models demonstrate varying degrees of success and capability in evaluating the key bioenergy themes.

- IAMs - provide the best modelling approach to analyse and forecast how bioenergy may fit with wider energy and environmental systems and to develop pathways for reducing emissions and achieving its target. However IAMs do not/ cannot capture the many other issues associated with sustainable bioenergy systems and the nuances between them.

- Energy System Models - have better coverage of different bioenergy processes and technologies and the different bioenergy feedstocks, although do no capture the wider environmental systems, economic and social issues.

- Specialist Bioenergy Models - are widely developed and applied to offer bespoke analysis approaches covering all the different research themes associated with bioenergy. However the restriction of these analyses to narrow systems boundaries and/ or specific case studies results in limited results where wider effects such as land-use change may not be captured.

It is not feasible to develop all-encompassing bioenergy models that capture all the nuances between different systems, but there is a strong argument for using multiple models in parallel where through 
application of their different approaches could collectively build more robust overall conclusions. This could be achieved through developing a versatile framework of models that are integrated, providing an overall 'modular modelling approach' to utilise the strengths and mitigate for the weaknesses of any given individual model.

\section{Acknowledgments}

The authors thank EPSRC, BBSRC and UK Supergen Bioenergy Hub (EP/S000771/1) who funded and supported this research.

\section{References}

[1] UNFCCC, Paris Agreement, Bonn, 2015. http://unfccc.int/resource/docs/2015/cop21/eng//09r01.pdf.

[2] World Economic Forum, These Countries have Committed to a Net-Zero Emissions Goal Could it Solve the Climate Crisis?, Cologny, Switzerland, n.d. https://www.weforum.org/agenda/2019/07/the-growing-list-of-countries-committing-to-a-netzero-emissions-goal/.

[3] IPCC, Climate Change 2014: Mitigation of Climate Change. Contribution of Working Group III to the Fifth Assessment Report of the Intergovernmental Panel on Climate Change, Geneva, 2014. https://www.ipcc.ch/site/assets/uploads/2018/02/ipcc_wg3_ar5_full.pdf.

[4] D.B. Goldstein, Renewables may be plunging in price, but efficiency remains the cornerstone of the clean energy economy, Electr. J. 31 (2018) 16-19. doi:10.1016/J.TEJ.2018.05.002.

[5] IRENA, Renewable PowerGeneration Costs in 2017, Abu Dhabi, 2017. https://www.irena.org//media/Files/IRENA/Agency/Publication/2018/Jan/IRENA_2017_Power_Costs_2018.pdf.

[6] G. Savvidis, K. Siala, C. Weissbart, L. Schmidt, F. Borggrefe, S. Kumar, et al., The gap between energy policy challenges and model capabilities, Energy Policy. 125 (2019) 503-520. doi:10.1016/J.ENPOL.2018.10.033.

[7] N. Strachan, B. Fais, H. Daly, Reinventing the Energy Modelling - Policy Interface, Nat. Commun. 1 (2016). https://www.nature.com/articles/nenergy201612.pdf?draft=marketing.

[8] European Commission, Renewable Energy Progress Report, Brussels, 2019. https://eurlex.europa.eu/legalcontent/EN/TXT/PDF/?uri=CELEX:52019DC0225\&qid=1559033163855\&from=EN.

[9] A.J. Welfle, Balancing Growing Global Bioenergy Resource Demands - Brazil's Biomass Potential and the Availability of Resources for Trade, Biomass Bioenergy. 105 (2017) 83-95. doi:10.1016/j.biombioe.2017.06.011.

[10] UK Supergen Bioenergy Hub, UK Bioenergy Researchers' Day, in: Glasgow, 2019.

[11] Clarivate Analytics, Web of Science, Web Sci. (2019).

[12] A.J. Welfle, P. Thornley, S. Cross, S. Syri, M. Mikael, Bioenergy Development in the UK \& Nordic Countries: A Comparison of Effectiveness of Support Policies for Sustainable Development of the Bioenergy Sector, TBC. TBC (n.d.).

[13] A. Roos, C. Rakos, The limits of modelling. Experiences with bioenergy in practice - could models have predicted this outcome?, Biomass and Bioenergy. 18 (2000) 331-340. doi:10.1016/S0961-9534(99)00097-5.

[14] H. Hotelling, The Economics of Exhaustible Resources, J. Polit. Econ. 39 (1931) 137-175.

[15] S. Shafiee, E. Topal, When will Fossil Fuel Reserves be Diminished?, Energy Policy. 37 (2008) 181-189.

[16] R. Slade, R. Saunders, R. Gross, A. Bauen, Energy from Biomass: the Size of the Global Resource, London, 2011.

[17] S. Rose, E. Kriegler, R. Bibas, K. Calvin, A. Popp, D. van Vuuren, et al., Bioenergy in Energy Transformation and Climate Management, Clim. Change. 123 (2013).

https://www.researchgate.net/publication/259634399_Bioenergy_in_energy_transformation_an d_climate_management.

[18] N. Bauer, S.K. Rose, S. Fujimori, D.P. van Vuuren, J. Weyant, M. Wise, et al., Global Energy Sector Emission Reductions and Bioenergy Use: Overview of the Bioenergy Demand Phase of the EMF-33 Model Comparison, Clim. Change. (2018). 
https://link.springer.com/article/10.1007\%2Fs10584-018-2226-y.

[19] H. Lotze-Campen, M. von Lampe, P. Kyle, S. Fujimori, P. Havlik, H. van Meijl, et al., Impacts of Increased Bioenergy Demand on Global Food Markets: an AgMIP Economic Model Intercomparison, Agric. Econ. 45 (2013) 103-116. https://onlinelibrary.wiley.com/doi/full/10.1111/agec.12092.

[20] L.M.H. Hall, A.R. Buckley, A review of energy systems models in the UK: Prevalent usage and categorisation, Appl. Energy. 169 (2016) 607-628. doi:10.1016/J.APENERGY.2016.02.044.

[21] S. Pye, F.G.N. Li, A. Petersen, O. Broad, W. McDowall, J. Price, et al., Assessing qualitative and quantitative dimensions of uncertainty in energy modelling for policy support in the United Kingdom, Energy Res. Soc. Sci. 46 (2018) 332-344. doi:10.1016/J.ERSS.2018.07.028.

[22] S. Bhattacharya, G. Timilsina, A Review of Energy System Models, Int. J. Energy Sect. Manag. 4 (2010) 494-518.

[23] B. Kretschmer, S. Peterson, Integrating bioenergy into computable general equilibrium models - A survey, Energy Econ. 32 (2010) 673-686. doi:10.1016/J.ENECO.2009.09.011.

[24] B. Wicke, F. van der Hilst, V. Daioglou, M. Banse, T. Beringer, S. Gerssen- Gondelach, et al., Model Collaboration for the Improved Assessment of Biomass Supply, Demand, and Impacts, GCB Bioenergy. 7 (2014) 422-437.

[25] T.W. Hertel, Applied General Equilibrium Analysis of Agricultural and Resource Policies, West Lafayette, 1999. https://www.gtap.agecon.purdue.edu/resources/download/11.pdf.

[26] D.-H. Lee, Econometric assessment of bioenergy development, Int. J. Hydrogen Energy. 42 (2017) 27701-27717. doi:10.1016/J.IJHYDENE.2017.08.055.

[27] J. Choumert Nkolo, P. Combes Motel, C. Guegang Djimeli, Income-generating Effects of Biofuel Policies: A Meta-analysis of the CGE Literature, Ecol. Econ. 147 (2018) 230-242. doi:10.1016/J.ECOLECON.2018.01.025.

[28] A. Bouët, B. V Dimaranan, H. Valin, Modeling the Global Trade and Environmental Impacts of Biofuel Policies, Washington D.C, 2010. http://www.ifpri.org/publication/modeling-global-tradeand-environmental-impacts-biofuel-policies.

[29] T. Hertel, J. Beckman, Commodity Price Volatility in the Biofuel Era: An Examination of the Linkages between Energy and Agricultural Markets, Cambridge, MA, 2011. https://www.nber.org/papers/w16824.pdf.

[30] D. Laborde, Assessing the Land Use Change Consequences of European Biofuel Policies, Washington D.C, 2011. http://ebrary.ifpri.org/utils/getfile/collection/p15738coll5/id/197/filename/198.pdf.

[31] F. van der Hilst, J. Verstegen, T. Zheliezna, O. Drozdova, A. Faaij, Integrated Spatiotemporal Modelling of Bioenergy Production Potentials, Agricultural Land Use, and Related GHG Balances; Demonstrated for Ukraine, Biofuels, Bioprod. Biorefining. 8 (2014) 391-411.

[32] S. Jablonski, N. Strachan, C. Brand, A. Bauen, The Role of Bioenergy in the UK's Energy Future Formulation \& Modelling of Long-Term UK Bioenergy Scenarios, Energy Policy. 38 (2010) 5799-5816.

[33] W. McDowall, G. Anandarajah, P. Dodds, J. Tomei, Implications of Sustainability Constraints on UK Bioenergy Development: Assessing Optimistic \& Precautionary Approaches with UK MARKAL, Energy Policy. 47 (2012) 424-436.

[34] H. van Meijl, I. Tsiropoulos, H. Bartelings, R. Hoefnagels, E. Smeets, A. Tabeau, et al., On the macro-economic impact of bioenergy and biochemicals - Introducing advanced bioeconomy sectors into an economic modelling framework with a case study for the Netherlands, Biomass and Bioenergy. 108 (2018) 381-397. doi:10.1016/J.BIOMBIOE.2017.10.040.

[35] G. Venturini, A. Pizarro-Alonso, M. Münster, How to maximise the value of residual biomass resources: The case of straw in Denmark, Appl. Energy. 250 (2019) 369-388. doi:10.1016/J.APENERGY.2019.04.166.

[36] S. Garcia-Freites, Biofuel production potentials in europe: sustainable use of cultivated land and pastures. part I: land productivity potentials, Biomass Convers. Biorefinery. (2019).

[37] G. Fischer, S. Prieler, H. van Velthuizen, S.M. Lensink, M. de Wit, Biofuel production potentials in Europe: Sustainable use of cultivated land and pastures. Part I: Land productivity potentials, Biomass and Bioenergy. 34 (2010) 159-172. doi:10.1016/J.BIOMBIOE.2009.07.008.

[38] R.M. Cuéllar-Franca, A. Azapagic, Carbon capture, storage and utilisation technologies: A 
critical analysis and comparison of their life cycle environmental impacts, J. CO2 Util. 9 (2015) 82-102. doi:10.1016/j.jcou.2014.12.001.

[39] A.J. Welfle, P. Gilbert, P. Thornley, A. Stephenson, Generating low-carbon heat from biomass: Life cycle assessment of bioenergy scenarios, J. Clean. Prod. 149 (2017) 448-460. doi:10.1016/j.jclepro.2017.02.035.

[40] A.J. Welfle, P. Gilbert, P. Thornley, Securing a Bioenergy Future without Imports, Energy Policy. 68 (2014) 249-266. doi:10.1016/j.biombioe.2014.08.001.

[41] A.J. Welfle, P. Gilbert, P. Thornley, Increasing biomass resource availability through supply chain analysis, Biomass and Bioenergy. 70 (2014) 249-266. doi:10.1016/j.biombioe.2014.08.001.

[42] S. Garcia-Freites, A. Welfle, A. Lea-Langton, P. Gilbert, P. Thornley, The potential of coffee stems gasification to provide bioenergy for coffee farms: a case study in the Colombian coffee sector, Biomass Convers. Biorefinery. (2019). doi:10.1007/s13399-019-00480-8.

[43] A. Gambhir, I. Butnar, P. Li, P. Smith, N. Strachan, A Review of Criticisms of Integrated Assessment Models and Proposed Approaches to Address These, through the Lens of BECCS, Energies. 12 (2019) 1747. https://doi.org/10.3390/en12091747.

[44] J. Weyant, Some Contributions of Integrated Assessment Models of Global Climate Change, Rev. Environ. Econ. Policy. 11 (2017) 115-137.

[45] AIM Project Team, AIM - Asia-Pacific Integrated Model, 2019. http://www-iam.nies.go.jp/aim/.

[46] University of Maryland, Global Change Assessment Model, Maryland, 2019. http://www.globalchange.umd.edu/about-us/.

[47] University College London, Model Concept, Solver and Details - IMACLIM, London, 2019. https://wiki.ucl.ac.uk/display/ADVIAM/Model+concept\%2C+solver+and+details+-+IMACLIM.

[48] PBL Netherlands Environment Assessment Agency, Integrated Model to Assess the Global Environment, Amsterdam, 2019. https://models.pbl.nl/image/index.php/Welcome_to_IMAGE_3.0_Documentation.

[49] IIASA, MESSAGE, Laxenburg, Austria, 2019. http://www.iiasa.ac.at/web/home/research/modelsData/MESSAGE/MESSAGE.en.html.

[50] Potsdam Institute for Climate Impact Research, REMIND, Potsdam, 2019. https://www.pikpotsdam.de/research/transformation-pathways/models/remind/remind.

[51] Energy Technology Systems Analysis Program, ETSAP-TIAM (TIMES Integrated Assessment Model), Gielen, Dolf, 2019. https:/iea-etsap.org/index.php/applications/global.

[52] European Institute on Economics and the Environment, World Induced Technical Change Hybrid, Milan, 2019. https://www. witchmodel.org/.

[53] B. Hare, R. Brecha, M. Schaeffer, Integrated Assessment Models: What are they and How do they Arrive at their Conclusions?, Potsdam, 2018. https://climateanalytics.org/media/climate_analytics_iams_briefing_oct2018.pdf.

[54] F. Creutzig, Economic and Ecological Views on Climate Change Mitigation with Bioenergy and Negative Emissions, GCB Bioenergy. 8 (2016) 4-10.

[55] V. Daioglou, J.C. Doelman, B. Wicke, A. Faaij, D.P. van Vuuren, Integrated assessment of biomass supply and demand in climate change mitigation scenarios, Glob. Environ. Chang. 54 (2019) 88-101. doi:10.1016/J.GLOENVCHA.2018.11.012.

[56] M. Hoogwijk, A. Faaij, B. Eickhout, Potentials of Biomass Energy Out to 2100 for Four IPCC SRES Land-Use Scenarios, Biomass Bioenergy. 29 (2005) 225-257.

[57] V. Chaturvedi, M. Hejazi, J. Edmonds, L. Clarke, P. Kyle, E. Davies, et al., Climate mitigation policy implications for global irrigation water demand, Mitig. Adapt. Strateg. Glob. Chang. 20 (2013) 389-407.

[58] H. Chum, A. Faaij, J. Moreira, G. Berndes, P. Dhamija, H. Dong, et al., Bioenergy. In IPCC Special Report on Renewable Energy Sources \& Climate Change Mitigation, Cambridge, New York, 2011.

[59] C. Gough, S. Garcia-Freites, C. Jones, S. Mander, B. Moore, C. Pereira, et al., Challenges to the use of BECCS as a keystone technology in pursuit of $1.5^{\circ} \mathrm{C}$, Glob. Sustain. (2018). doi:10.1017/sus.2018.3.

[60] N. Hughes, N. Strachan, Methodological review of UK and international low carbon scenarios, 
Energy Policy. 38 (2010) 6056-6065. doi:10.1016/J.ENPOL.2010.05.061.

[61] T. Hooper, M.C. Austen, N. Beaumont, P. Heptonstall, R.A. Holland, I. Ketsopoulou, et al., Do energy scenarios pay sufficient attention to the environment? Lessons from the UK to support improved policy outcomes, Energy Policy. 115 (2018) 397-408. doi:10.1016/J.ENPOL.2018.01.028.

[62] R. Holland, I. Ketsopoulou, N. Beaumont, M. Austen, T. Hooper, R. Gross, et al., UKERC Technology and Policy Assessment - How Consistent and Comparable are Ecosystem Services and Energy System Scenarios?, London, 2016.

http://www.ukerc.ac.uk/publications/working-paper-how-consistent-and-comparable-areecosystem-services-and-energy-system-scenarios-.html.

[63] S. Raman, A. Mohr, R. Helliwell, B. Ribeiro, O. Shortall, R. Smith, et al., Integrating social and value dimensions into sustainability assessment of lignocellulosic biofuels, Biomass and Bioenergy. 82 (2015) 49-62. doi:10.1016/J.BIOMBIOE.2015.04.022.

[64] R.A. Holland, N. Beaumont, T. Hooper, M. Austen, R.J.K. Gross, P.J. Heptonstall, et al., Incorporating ecosystem services into the design of future energy systems, Appl. Energy. 222 (2018) 812-822. doi:10.1016/J.APENERGY.2018.04.022.

[65] IEA, IRENA, Global Renewable Energy Policies \& Measures Database, (2019). www.iea.org/policiesandmeasures/renewableenergy/.

[66] J.L. Aleixandre-Tudó, L. Castelló-Cogollos, J.L. Aleixandre, R. Aleixandre-Benavent, Renewable energies: Worldwide trends in research, funding and international collaboration, Renew. Energy. 139 (2019) 268-278. doi:10.1016/J.RENENE.2019.02.079.

[67] M. Nachmany, J. Setzer, Policy Brief - Global Trends in Climate Change Legislation and Litigation: 2018 Snapshot, London, 2018. http://www.Ise.ac.uk/GranthamInstitute/wpcontent/uploads/2018/04/Global-trends-in-climate-change-legislation-and-litigation-2018snapshot-3.pdf.

[68] A. Alcayde, F.G. Montoya, R. Baños, A. Perea-Moreno, F. Manzano-Agugliaro, Analysis of Research Topics and Scientific Collaborations in Renewable Energy Using Community Detection, Sustainability. 10 (2018).

[69] Institute for European Environmental Policy, Securing Biomass for Energy - Developing an Environmentally Responsible Industry for the UK Now \& into the Future, 2011.

http://www.woodlandtrust.org.uk/en/about-us/publications/Documents/ieep-uk-responsiblebioenergy-2011-08-16-final.pdf.

[70] T. Searchinger, R. Heimlich, Avoiding Bioenergy Competition for Food Crops and Land, Washington D.C, 2014. https://www.agrilinks.org/sites/default/files/resource/files/WRI Avoiding Bioenergy Competition for Food Crops and Land.pdf.

[71] T. Horschig, D. Thrän, Are decisions well supported for the energy transition? A review on modeling approaches for renewable energy policy evaluation, Energy. Sustain. Soc. 7 (2017). https://link.springer.com/content/pdf/10.1186\%2Fs13705-017-0107-2.pdf.

[72] W. Poortinga, A. Spence, L. Whitmarsh, S. Capstick, N. Pidgeon, Uncertain Climate: An Investigation into Public Scepticism about Anthropogenic Climate Change, Glob. Environ. Chang. 21 (2011) 1015-1024.

https://www.sciencedirect.com/science/article/pii/S0959378011000288.

[73] T. Schinko, G. Bachner, S.P. Schleicher, K.W. Steininger, Modeling for insights not numbers: The long-term low-carbon transformation, Atmósfera. 30 (2017) 137-161. doi:10.20937/ATM.2017.30.02.05.

[74] P. Rochedo, Development of a Global Integrated Energy Model to Evaluate the Brazilian Role in Climate Change Mitigation Scenarios, Rio de Janeiro, 2016.

[75] K. Jiang, X. Zhuang, R. Miao, C. He, China's Role in Attaining the Global 2C Target, Clim. Policy. 13 (2013). 10.1080/14693062.2012.746070.

[76] G. Luderer, M. Pehl, A. Arvesen, T. Gibon, B.L. Bodirsky, H. Sytze de Boer, et al., Environmental Co-Benefits and Adverse Side-Effects of Alternative Power Sector Decarbonisation Strategies, Nat. Commun. 10 (2019). https://www.nature.com/articles/s41467019-13067-8. 


\section{Supplementary Materials \\ Supplementary Materials 1: Description of Research Methodology}

\section{Literature Review}

A comprehensive literature review was undertaken to evaluate the different types of energy models and to analyse how they are applied within bioenergy research. This review was completed focusing on published academic literature, Government reports and through engagement with UK academic, government and industry stakeholders at a UK Supergen Bioenergy Hub event [10]. The focus of the literature review was to document the varying approaches that different models have to bioenergy research and to highlight the performance of these models in analysing key bioenergy research questions.

\section{Building the Bioenergy Literature Database}

The Bioenergy Literature Database (BLD) database was developed as a research tool to allow analysis of the changing characteristics of bioenergy literature and how these publications use modelling within their methods and analyses. The BLD was designed with the aim of collating a full list of all the bioenergy research papers published between 2000 and 2018. This timeframe was chosen because 2000 represents a time when bioenergy started to gain policy focus and traction as an alternative energy source, whilst 2018 was the last year where a full year's publication record was available at the time of writing this paper.

The BLD was constructed sourcing references from The Web of Science - a science citation indexing website produced by the Institute for Scientific Information and now operated by Clarivate Analytics, that allows comprehensive citation searches through multiple databases that reference crossdisciplinary research [11]. A systematic process of bioenergy publication searches was completed using the Web of Science, collating the results of all searches within a Microsoft Excel database (BLD). These searches focused on bioenergy literature that made references to the key words and phrases as listed within Table 1. This list of key search terms and the choice of specific named models included within the searches were developed following consultation with UK academic, government and industry stakeholders at a UK Supergen Bioenergy Hub event [10].

Each research publication entry included within the BLD captured key information including the Authors, Title, Year, Host Publication and the Full Abstract. A process of 'database cleaning' was then completed to remove any duplicate entries captured across the different searches. A further bioenergy 'entry test' was then completed to ensure that entries within the BLD were focused on biomass/ bioenergy research - this was achieved using IF Statements to search for either the terms 'biomass' or 'bioenergy' within the Abstract, removing entries that did not. The final BLD captured 124,285 biomass/ bioenergy research papers published between 2000 and 2018.

\section{Analysis using the Bioenergy Literature Database}

Analysis using the BLD was undertaken by creating a tally of the number of times that different key words appear within the abstract of each entry within the database. The presence of key words was identified using IF Statements. For example if a paper is focused on the modelling of biofuels using the IMAGE model, as long as these phrases are included in the abstract the paper would be recorded with a positive ' 1 ' for both the 'biofuel' and 'IMAGE' calculations, if these phrases were not present the paper within the BLD would be recorded with a ' 0 '.

Building on a methodology developed by Welfle et al [12], this analysis relies on the assumption that key words describing the content of the paper will be included in the abstract. Through creating a tally of the coverage of key search term the BLD was used to analyse the changing number of papers covering different bioenergy issues, the changing use of different types of models and to highlight the extent that different models are used to analyse different themes of bioenergy research. 
Supplementary Table 1: Search Terms for Web of Knowledge Searches for Building the Bioenergy Literature Database

\begin{tabular}{|c|c|c|c|c|c|c|}
\hline Category & Themes & \multicolumn{5}{|c|}{ Specific Search Words } \\
\hline \multirow{2}{*}{ Themes } & Biomass & - Biomass & & & & \\
\hline & Bioenergy & ○ Bioenergy & & & & \\
\hline Modelling & Modelling & $\begin{array}{ll}\circ & \text { Model } \\
\circ & \text { Models }\end{array}$ & $\circ$ & Modeling & ○ & Modelling \\
\hline \multirow{8}{*}{ IAMs } & Asia-Pacific Integrated Model & $\begin{array}{ll}\circ & \text { AIM/CGE } \\
\circ & \text { Asia-Pacific Integrated Model }\end{array}$ & $\begin{array}{l}\circ \\
\circ\end{array}$ & $\begin{array}{l}\text { CGE Model } \\
\text { AIM Model }\end{array}$ & ○ & Computable General Equilibrium Model \\
\hline & GCAM & $\circ \quad G C A M$ & o & GCAM Model & o & Global Change Assessment Model \\
\hline & IMACLIM & ○ IMACLIM Model & o & IMACLIM & & \\
\hline & IMAGE & $\circ \quad$ IMAGE Model & o & IMAGE IAM & o & Integrated Model to Assess the Global Environment \\
\hline & MESSAGE-GLOBIOM & - MESSAGE Model & o & MESSAGE & & \\
\hline & REMIND-MAgPIE & $\circ \quad$ REMIND Model & ○ & REMIND & o & Regional Model of Investments \& Development \\
\hline & WITCH & ○ WITCH Model & o & WITCH & o & World Induced Technical Change Hybrid \\
\hline & TIAM & $\begin{array}{ll}\circ & \text { TIMES Model } \\
\circ & \text { Integrated MARKAL-EFOM } \\
& \text { System }\end{array}$ & $\begin{array}{l}\circ \\
\circ \\
\circ\end{array}$ & $\begin{array}{l}\text { MARKAL } \\
\text { TIAM Model } \\
\text { MARKAL-EFOM }\end{array}$ & & $\begin{array}{l}\text { TIAM } \\
\text { TIMES Integrated Assessment Model }\end{array}$ \\
\hline \multirow{13}{*}{$\begin{array}{l}\text { Energy } \\
\text { System } \\
\text { Models }\end{array}$} & AGLINK & $\circ \quad A G L I N K$ Model & o & AGLINK & & \\
\hline & BALMOREL & $\circ \quad B A L M O R E L$ Model & o & BALMOREL & & \\
\hline & DECC 2050 calculator & ○ DECC 2050 calculator Model & o & DECC 2050 calculator & & \\
\hline & DER-CAM & ○ DER-CAM Model & o & DER-CAM & & \\
\hline & DNE21 & ○ DNE21 Model & o & DNE21 & & \\
\hline & DynEMo & ○ DynEMo Model & o & DynEMo & & \\
\hline & E4cas & $\circ \quad$ E4cast Model & o & E4cas & & \\
\hline & EMCAS & ○ EMCAS Model & o & EMCAS & & \\
\hline & EMPS & - EMPS Model & o & EMPS & & \\
\hline & EnergyPLAN & ○ EnergyPLAN Model & o & EnergyPLAN & & \\
\hline & ENPEP-BALANCE & - ENPEP-BALANCE Model & o & ENPEP-BALANCE & & \\
\hline & ESME & ○ ESME Model & o & ESME & & \\
\hline & ETM-UCL & - ETM-UCL Model & o & ETM-UCL & & \\
\hline
\end{tabular}




\begin{tabular}{|c|c|c|c|c|c|}
\hline & FAPRI-CARD & ○ & FAPRI-CARD Model & $\circ$ & FAPRI-CARD \\
\hline & GEM-E3 & o & GEM-E3 Model & $\circ$ & GEM-E3 \\
\hline & IKARUS & ○ & IKARUS Model & $\circ$ & IKARUS \\
\hline & MERGE-ETL & $\circ$ & MERGE-ETL Model & $\circ$ & MERGE-ETL \\
\hline & METIS & $\circ$ & METIS Model & $\circ$ & METIS \\
\hline & MiniCAM & $\circ$ & MiniCAM Model & $\circ$ & MiniCAM \\
\hline & OSeMOSYS & o & OSeMOSYS Model & $\circ$ & OSEMOSYS \\
\hline & PERSEUS & o & PERSEUS Model & $\circ$ & PERSEUS \\
\hline & POLES & $\circ$ & POLES Model & $\circ$ & POLES \\
\hline & RAMSES & ○ & RAMSES Model & $\circ$ & RAMSES \\
\hline & SPLAT & $\circ$ & SPLAT Model & $\circ$ & SPLAT \\
\hline & TEMOA & 0 & TEMOA Model & $\circ$ & TEMOA \\
\hline & TIAM-UCL & $\circ$ & TIAM-UCL Model & $\circ$ & TIAM-UCL \\
\hline & TIMER & $\circ$ & TIMER Model & $\circ$ & TIMER \\
\hline & UK TIMES & ○ & UK TIMES Model & $\circ$ & UK TIMES \\
\hline & WEPS & o & WEPS Model & $\circ$ & WEPS \\
\hline & WILMAR & $\circ$ & WILMAR Model & $\circ$ & WILMAR \\
\hline \multirow{13}{*}{$\begin{array}{c}\text { Specialist } \\
\text { Models }\end{array}$} & BRM & ० & Biomass Resource Model & $\circ$ & $B R M$ \\
\hline & BVCM & $\circ$ & $B V C M$ & $\circ$ & Bioenergy Value Chain Model \\
\hline & CARBINE & $\circ$ & CARBINE Model & $\circ$ & CARBINE \\
\hline & CO2Fix & $\circ$ & CO2Fix Model & $\circ$ & CO2Fix \\
\hline & COMPOSE & o & COMPOSE Model & $\circ$ & COMPOSE Project \\
\hline & EFI-GTM & o & EFI-GTM Model & $\circ$ & EFI-GTM \\
\hline & EFISCEN & $\circ$ & EFISCEN Model & $\circ$ & EFISCEN \\
\hline & GAINS & ○ & GAINS Model & $\circ$ & Greenhouse Gas and Air Pollution Interactions and Synergies \\
\hline & HYDROGEMS & $\circ$ & HYDROGEMS Model & $\circ$ & HYDROGEMS \\
\hline & INFORSE & $\circ$ & INFORSE Model & $\circ$ & INFORSE \\
\hline & Invert & ○ & Invert Model & $\circ$ & Invert \\
\hline & LEAP & $\circ$ & LEAP Model & $\circ$ & LEAP \\
\hline & PLEXOS & $\circ$ & PLEXOS Model & $\circ$ & PLEXOS \\
\hline
\end{tabular}




\begin{tabular}{|c|c|c|c|c|c|}
\hline & SHIPMod & o & SHIPMod Model & $\circ$ & SHIPMod \\
\hline & ToSIA & o & ToSIA Model & o & ToSIA \\
\hline & $\begin{array}{l}\text { Solid and Gaseous Biomass } \\
\text { Carbon Calculator }\end{array}$ & ○ & $\begin{array}{l}\text { Solid \& Gaseous Biomass } \\
\text { Carbon Calculator }\end{array}$ & $\circ$ & Solid and Gaseous Biomass Carbon Calculator \\
\hline & WASP & o & WASP Model & o & WASP \\
\hline \multirow{13}{*}{$\begin{array}{l}\text { Bioenergy } \\
\text { Feedstocks }\end{array}$} & Forestry & ० & Forestry & ○ & Forest \\
\hline & Algae & o & Algae & $\circ$ & Alga \\
\hline & Briquettes & o & Briquette & o & Briquettes \\
\hline & Pellets & o & Pellet & o & Pellets \\
\hline & Chips & o & Chip & o & Chips \\
\hline & Wood & ० & Wood & & \\
\hline & Waste & o & Waste & $\circ$ & Wastes \\
\hline & Residues & o & Residues & o & Residue \\
\hline & Lignocellulosic & o & Lignocellulosic & & \\
\hline & Energy Crops & o & Energy Crops & & \\
\hline & 1st Generation & & $\begin{array}{l}\text { 1st Generation } \\
1 \text { st Gen }\end{array}$ & $\begin{array}{l}\circ \\
\circ\end{array}$ & $\begin{array}{ll}\text { First Generation } & \\
\text { First Gen } & \circ\end{array}$ \\
\hline & 2nd Generation & & $\begin{array}{l}\text { 2nd Generation } \\
\text { 2nd Gen }\end{array}$ & $\begin{array}{l}\circ \\
\circ\end{array}$ & $\begin{array}{l}\text { Second Generation } \\
\text { Second Gen }\end{array} \quad \circ \quad 2 G$ \\
\hline & 3rd Generation & & $\begin{array}{l}\text { 3rd Generation } \\
\text { 3rd Gen }\end{array}$ & $\begin{array}{l}\circ \\
\circ \\
\circ\end{array}$ & $\begin{array}{l}\text { Third Generation } \\
\text { Third Gen }\end{array}$ \\
\hline \multirow{9}{*}{$\begin{array}{l}\text { Modelling } \\
\text { Approaches }\end{array}$} & IAMs & o & $I A M$ & $\circ$ & Integrated Assessment Model \\
\hline & Energy System Model & o & ESM & o & Energy System Model \\
\hline & Bottom Up & o & Bottom-Up & o & Bottom Up \\
\hline & Top Down & o & Top-Down & $\circ$ & Top Down \\
\hline & Resource Modelling & ○ & Resource Model & $\circ$ & Resource Modelling \\
\hline & Process Modelling & o & Process Modelling & o & Process Model \\
\hline & TEA & & $\begin{array}{l}\text { TEA } \\
\text { Techno Economic Assessment }\end{array}$ & ० & Techno-Economic Assessment $\quad \circ$ Techno-Economic \\
\hline & GIS & ○ & GIS & ○ & Geographic Information System \\
\hline & LCA & o & $\angle C A$ & $\circ$ & Life Cycle Assessment \\
\hline
\end{tabular}




\begin{tabular}{|c|c|c|c|c|c|c|c|}
\hline \multirow{14}{*}{$\begin{array}{c}\text { Bioenergy } \\
\text { Processes \& } \\
\text { Technologies }\end{array}$} & BECCS \& CCS & $\begin{array}{l}\circ \\
\circ\end{array}$ & $\begin{array}{l}\text { Carbon Capture Storage } \\
\text { Carbon Capture }\end{array}$ & $\begin{array}{l}\circ \\
\circ\end{array}$ & $\begin{array}{l}\text { BECCS } \\
\text { Bio CCS }\end{array}$ & ○ & $\operatorname{cCS}$ \\
\hline & Combustion & o & Combustion & & & & \\
\hline & Pyrolysis & ० & Pyrolysis & & & & \\
\hline & Gasification & ○ & Gasification & & & & \\
\hline & Torrefaction & o & Torrefaction & & & & \\
\hline & Anaerobic Digestion & ० & Anaerobic Digestion & & & & \\
\hline & Co-firing & ○ & Co-firing & ○ & Cofring & & \\
\hline & Thermo-chemical & o & Thermochemical & ○ & Thermo-chemical & & \\
\hline & Catalysis & o & Catalytic & o & Catalysis & & \\
\hline & Bio-chemicals & & $\begin{array}{l}\text { Biochemical } \\
\text { Bio-chemical }\end{array}$ & o & Biochemicals & ○ & Bio-chemicals \\
\hline & Fermentation & ○ & Fermentation & & & & \\
\hline & Dyring & ○ & Drying & ○ & Dry & & \\
\hline & Chipping & o & Chipping & & & & \\
\hline & Pelletising & ○ & Pelletising & $\circ$ & Pelletizing & & \\
\hline \multirow{11}{*}{$\begin{array}{l}\text { Bioenergy } \\
\text { Systems } \\
\text { Issues }\end{array}$} & Bio-economy & & $\begin{array}{l}\text { Bio-economy } \\
\text { Bio economy }\end{array}$ & $\begin{array}{l}0 \\
\circ \\
\circ\end{array}$ & $\begin{array}{l}\text { Bioeconomy } \\
\text { Economic }\end{array}$ & $\begin{array}{l}\circ \\
\circ\end{array}$ & $\begin{array}{l}\text { Economy } \\
\text { Economics }\end{array}$ \\
\hline & Environment & o & Environment & & & & \\
\hline & Emissions \& GHGs & & $\begin{array}{l}\text { Emissions } \\
\text { Emission }\end{array}$ & $\begin{array}{l}\circ \\
\circ\end{array}$ & $\begin{array}{l}\text { GHG } \\
\text { GHGs }\end{array}$ & $\begin{array}{l}\circ \\
\circ\end{array}$ & $\begin{array}{l}\text { CO2 } \\
\text { Carbon }\end{array}$ \\
\hline & ILUC & o & ILUC & ० & Indirect Land Use Change & & \\
\hline & Sustainability & o & Sustainability & o & Sustainable & & \\
\hline & Climate Change & ○ & Climate Change & $\circ$ & Climate & & \\
\hline & Yields \& Productivity & & $\begin{array}{l}\text { Yield } \\
\text { Feedstock Yield }\end{array}$ & $\circ$ & Crop Yield & ० & Productivity \\
\hline & Trade & $\circ$ & Trade & & & & \\
\hline & Water & ० & Water & & & & \\
\hline & Deforestation & $\circ$ & Deforestation & & & & \\
\hline & Forestation & 0 & Forestation & & & & \\
\hline
\end{tabular}




\begin{tabular}{|c|c|c|c|c|c|c|}
\hline & Ecosystems \& Biodiversity & o $\quad$ Biodiversity & o & Ecosystems & o & Ecosystem \\
\hline & Jobs, Training \& Skills & $\begin{array}{ll}\circ & \text { Jobs } \\
\circ & \text { Employment }\end{array}$ & o & Skills & ० & Training \\
\hline & Land Use & $\circ \quad$ Land & $\circ$ & Land Use & $\circ$ & Land-Use \\
\hline \multirow{9}{*}{$\begin{array}{l}\text { Bioenergy } \\
\text { Vectors }\end{array}$} & BioPower & $\begin{array}{ll} & \text { Power } \\
\circ & \text { Biopower } \\
\circ & \text { Bio-power }\end{array}$ & & $\begin{array}{l}\text { Biomass Power } \\
\text { Bio-electricity }\end{array}$ & $\begin{array}{l}\circ \\
\circ\end{array}$ & $\begin{array}{l}\text { Bio power } \\
\text { Bioelectricity }\end{array}$ \\
\hline & BioHeat & $\begin{array}{ll} & \text { Bioenergy Heat } \\
\circ & \text { Bioheat }\end{array}$ & $\begin{array}{l}0 \\
0 \\
0\end{array}$ & $\begin{array}{l}\text { Bio-heat } \\
\text { Biomass Heat }\end{array}$ & $\begin{array}{l}\circ \\
\circ\end{array}$ & $\begin{array}{l}\text { Bio-thermal } \\
\text { Bio thermal }\end{array}$ \\
\hline & Transport Biofuels & $\begin{array}{ll} & \text { Transport } \\
\circ & \text { Biomass Transport }\end{array}$ & $\begin{array}{l}0 \\
0 \\
0\end{array}$ & $\begin{array}{l}\text { Bioenergy Transport } \\
\text { Transport Fuel }\end{array}$ & ० & Biofuel \\
\hline & Aviation & - Aviation & & & & \\
\hline & Heavy Goods Haulage & - Haulage & o & Heavy Goods & o & Trucks \\
\hline & Maritime & ○ Shipping & o & Maritime & & \\
\hline & Bio-chemicals & $\begin{array}{ll} & \text { Bioenergy Chemicals } \\
\circ & \text { Biomass Chemicals }\end{array}$ & $\begin{array}{l}\circ \\
\circ\end{array}$ & $\begin{array}{l}\text { Biochemicals } \\
\text { Bio-chemicals }\end{array}$ & $\begin{array}{l}\circ \\
\circ\end{array}$ & $\begin{array}{l}\text { Chemical Sector } \\
\text { Chemicals }\end{array}$ \\
\hline & Bio-syngas & $\begin{array}{ll} & \text { Bioenergy Syngas } \\
\circ & \text { Biomass Syngas }\end{array}$ & $\begin{array}{l}\circ \\
\circ\end{array}$ & $\begin{array}{l}\text { Syngas } \\
\text { Biosyngas }\end{array}$ & ० & Bio-syngas \\
\hline & Ecosystem Services & $\begin{array}{ll}\circ & \text { Ecosystem Services } \\
\circ & \text { Ecosystem Service } \\
\circ & \text { Flooding }\end{array}$ & & $\begin{array}{l}\text { Decontamination } \\
\text { De-contamination }\end{array}$ & $\begin{array}{l}\circ \\
\circ\end{array}$ & $\begin{array}{l}\text { Phytoremediation } \\
\text { Phyto-remediation }\end{array}$ \\
\hline
\end{tabular}


Supplementary Table 2: Total Number of Bioenergy Research Paper Published

\begin{tabular}{|l|c|c|c|c|}
\hline & $\begin{array}{c}\text { Biomass Focused } \\
\text { Research Papers }\end{array}$ & $\begin{array}{c}\text { Boenergy Focused } \\
\text { Research Papers }\end{array}$ & $\begin{array}{c}\text { Papers Applying } \\
\text { Modelling Analyses }\end{array}$ & $\begin{array}{c}\text { Papers Applying } \\
\text { Specific Named } \\
\text { Models }\end{array}$ \\
\hline 2000 & 1,976 & 36 & 711 & 8 \\
\hline 2001 & 2,064 & 23 & 765 & 6 \\
\hline 2002 & 2,064 & 30 & 854 & 7 \\
\hline 2003 & 1,795 & 46 & 1015 & 8 \\
\hline 2004 & 2,188 & 23 & 964 & 10 \\
\hline 2005 & 2,296 & 55 & 1,123 & 9 \\
\hline 2006 & 2,663 & 64 & 1,309 & 13 \\
\hline 2007 & 2,984 & 111 & 1,582 & 22 \\
\hline 2008 & 3,480 & 170 & 1,644 & 27 \\
\hline 2009 & 4,453 & 251 & 1,990 & 26 \\
\hline 2010 & 5,383 & 316 & 2,254 & 26 \\
\hline 2011 & 6,498 & 471 & 2,506 & 37 \\
\hline 2012 & 7,094 & 522 & 2,855 & 58 \\
\hline 2013 & 8,123 & 626 & 3,079 & 75 \\
\hline 2014 & 11,812 & 713 & 3,499 & 60 \\
\hline 2015 & 14,164 & 870 & 3,786 & 3,988 \\
\hline 2016 & 14,053 & 846 & 4,166 & 70 \\
\hline 2017 & 14,973 & 955 & & 76 \\
\hline 2018 & 12,895 & 848 & & 9 \\
\hline
\end{tabular}


Supplementary Table 3: Published Papers Focused on Different Themes of Bioenergy Research

\begin{tabular}{|l|c|c|c|c|}
\hline & Bioenergy Feedstocks & $\begin{array}{c}\text { Bioenergy Processes \& } \\
\text { Technologies }\end{array}$ & $\begin{array}{c}\text { Bioenergy Systems } \\
\text { Issues }\end{array}$ & Bioenergy Vectors \\
\hline 2000 & 821 & 959 & 2,324 & 218 \\
\hline 2001 & 813 & 968 & 2,397 & 229 \\
\hline 2002 & 901 & 1,007 & 2,454 & 254 \\
\hline 2003 & 792 & 691 & 2,336 & 281 \\
\hline 2004 & 1,020 & 864 & 2,711 & 318 \\
\hline 2005 & 1,100 & 944 & 2,963 & 337 \\
\hline 2006 & 1,328 & 1,122 & 3,462 & 479 \\
\hline 2007 & 1,434 & 1,345 & 3,897 & 598 \\
\hline 2008 & 1,777 & 1,612 & 4,611 & 821 \\
\hline 2009 & 2,351 & 2,270 & 6,398 & 1,145 \\
\hline 2010 & 2,830 & 2,882 & 7,423 & 1,345 \\
\hline 2011 & 3,821 & 3,525 & 9,098 & 1,905 \\
\hline 2012 & 4,190 & 4,005 & 10,484 & 2,337 \\
\hline 2013 & 5,112 & 4,759 & 11,812 & 2,903 \\
\hline 2014 & 6,327 & 5,084 & 16,310 & 3,560 \\
\hline 2015 & 7,729 & 6,167 & 19,597 & 3,779 \\
\hline 2016 & 8,021 & 6,657 & 20,478 & 4,005 \\
\hline 2017 & 8,553 & 7,104 & 21,740 & 3,924 \\
\hline 2018 & 8,273 & 7,706 & 20,221 & \\
\hline
\end{tabular}


Supplementary Table 4: Published Papers Using Focused on Different Categories of Models

\begin{tabular}{|c|c|c|c|}
\hline & Integrated Assessment Models & Energy System Models & Specialist Models \\
\hline 2000 & 2 & 5 & 2 \\
\hline 2001 & 1 & 3 & 3 \\
\hline 2002 & 1 & 6 & 5 \\
\hline 2003 & 2 & 2 & 6 \\
\hline 2004 & 1 & 2 & 6 \\
\hline 2005 & 2 & 2 & 6 \\
\hline 2006 & 2 & 1 & 6 \\
\hline 2007 & 3 & 4 & 7 \\
\hline 2008 & 4 & 3 & 11 \\
\hline 2009 & 8 & 7 & 7 \\
\hline 2010 & 11 & 5 & 9 \\
\hline 2011 & 9 & 10 & 13 \\
\hline 2012 & 10 & 7 & 20 \\
\hline 2013 & 13 & 11 & 18 \\
\hline 2014 & 24 & 14 & 19 \\
\hline 2015 & 36 & 21 & 20 \\
\hline 2016 & 33 & 8 & 18 \\
\hline 2017 & 32 & 8 & \\
\hline 2018 & 34 & 18 & \\
\hline
\end{tabular}


Supplementary Table 5: Modelling Approaches Applied within Specialist Bioenergy Models

\begin{tabular}{|c|c|c|c|c|c|c|c|c|c|}
\hline & $\begin{array}{l}\text { Integrated } \\
\text { Assessment } \\
\text { Models }\end{array}$ & $\begin{array}{l}\text { Energy System } \\
\text { Models }\end{array}$ & $\begin{array}{l}\text { Bottom-Up } \\
\text { Modelling }\end{array}$ & $\begin{array}{l}\text { Top-Down } \\
\text { Modelling }\end{array}$ & $\begin{array}{l}\text { Resource } \\
\text { Modelling }\end{array}$ & $\begin{array}{l}\text { Process } \\
\text { Modelling }\end{array}$ & $\begin{array}{c}\text { Techno- } \\
\text { Economic } \\
\text { Assessment }\end{array}$ & $\begin{array}{l}\text { Geographic } \\
\text { Information } \\
\text { Systems }\end{array}$ & $\begin{array}{l}\text { Life Cycle } \\
\text { Assessment }\end{array}$ \\
\hline 2000 & 1 & 7 & 21 & 26 & 0 & 5 & 6 & 48 & 1 \\
\hline 2001 & 1 & 8 & 18 & 32 & 0 & 8 & 6 & 65 & 1 \\
\hline 2002 & 0 & 13 & 33 & 45 & 0 & 10 & 7 & 66 & 1 \\
\hline 2003 & 0 & 9 & 30 & 46 & 0 & 10 & 9 & 53 & 6 \\
\hline 2004 & 2 & 15 & 42 & 38 & 0 & 9 & 3 & 94 & 4 \\
\hline 2005 & 0 & 9 & 39 & 52 & 0 & 8 & 8 & 75 & 11 \\
\hline 2006 & 3 & 5 & 54 & 67 & 3 & 14 & 6 & 98 & 7 \\
\hline 2007 & 0 & 8 & 52 & 62 & 0 & 13 & 7 & 82 & 11 \\
\hline 2008 & 2 & 17 & 60 & 70 & 2 & 11 & 9 & 124 & 14 \\
\hline 2009 & 0 & 12 & 51 & 49 & 2 & 13 & 9 & 165 & 34 \\
\hline 2010 & 4 & 28 & 54 & 58 & 3 & 21 & 23 & 193 & 34 \\
\hline 2011 & 4 & 36 & 61 & 63 & 1 & 23 & 26 & 275 & 58 \\
\hline 2012 & 3 & 58 & 65 & 67 & 2 & 18 & 25 & 244 & 79 \\
\hline 2013 & 5 & 81 & 83 & 86 & 3 & 25 & 34 & 311 & 74 \\
\hline 2014 & 14 & 143 & 85 & 81 & 5 & 22 & 55 & 415 & 108 \\
\hline 2015 & 12 & 178 & 92 & 86 & 2 & 37 & 66 & 463 & 114 \\
\hline 2016 & 13 & 154 & 90 & 86 & 2 & 39 & 99 & 526 & 100 \\
\hline 2017 & 11 & 157 & 82 & 90 & 4 & 38 & 120 & 541 & 137 \\
\hline 2018 & 21 & 143 & 90 & 94 & 5 & 41 & 138 & 543 & 132 \\
\hline
\end{tabular}


Supplementary Table 6: Coverage of Bioenergy Research Themes by Different Types of Bioenergy Models - Bioenergy Feedstocks

\begin{tabular}{|c|c|c|c|c|c|c|c|c|c|c|c|c|c|}
\hline & Published Papers & \multicolumn{3}{|c|}{ IAMs } & \multicolumn{3}{|c|}{ Energy System Models } & \multicolumn{3}{|c|}{ Specialist Models (named) } & \multicolumn{3}{|c|}{ Specialist Models (general) } \\
\hline \multirow{10}{*}{ 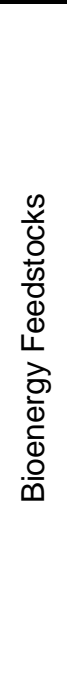 } & Forestry & \multirow{10}{*}{117} & 49 & $41.88 \%$ & \multirow{10}{*}{75} & 18 & $24.00 \%$ & \multirow{10}{*}{132} & 47 & $35.61 \%$ & \multirow{10}{*}{19,138} & 5,870 & $30.67 \%$ \\
\hline & Briquettes & & - & $0.00 \%$ & & 1 & $1.33 \%$ & & - & $0.00 \%$ & & 54 & $0.28 \%$ \\
\hline & Pellets & & 1 & $0.85 \%$ & & 2 & $2.67 \%$ & & 4 & $3.03 \%$ & & 465 & $2.43 \%$ \\
\hline & Chips & & 2 & $1.71 \%$ & & 2 & $2.67 \%$ & & 3 & $2.27 \%$ & & 380 & $1.99 \%$ \\
\hline & Wastes & & 12 & $10.26 \%$ & & 13 & $17.33 \%$ & & 7 & $5.30 \%$ & & 3,403 & $17.78 \%$ \\
\hline & Residues & & 4 & $3.42 \%$ & & 16 & $21.33 \%$ & & 12 & $9.09 \%$ & & 1,435 & $7.50 \%$ \\
\hline & Lignocellulosic & & 3 & $2.56 \%$ & & 3 & $4.00 \%$ & & 9 & $6.82 \%$ & & 1,144 & $5.98 \%$ \\
\hline & Energy Crops & & 14 & $11.97 \%$ & & 1 & $1.33 \%$ & & 5 & $3.79 \%$ & & 618 & $3.23 \%$ \\
\hline & 1st Generation & & 1 & $0.85 \%$ & & - & $0.00 \%$ & & 1 & $0.76 \%$ & & 117 & $0.61 \%$ \\
\hline & 2nd Generation & & 2 & $1.71 \%$ & & 1 & $1.33 \%$ & & 2 & $1.52 \%$ & & 206 & $1.08 \%$ \\
\hline
\end{tabular}


Supplementary Table 7: Coverage of Bioenergy Research Themes by Different Types of Bioenergy Models - Bioenergy Processes \& Technologies

\begin{tabular}{|c|c|c|c|c|c|c|c|c|c|c|c|c|c|}
\hline & Published Papers & \multicolumn{3}{|c|}{ IAMs } & \multicolumn{3}{|c|}{ Energy System Models } & \multicolumn{3}{|c|}{ Specialist Models (named) } & \multicolumn{3}{|c|}{ Specialist Models (general) } \\
\hline \multirow{10}{*}{ 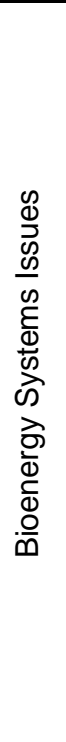 } & BECCS \& CCS & \multirow{10}{*}{89} & 45 & $50.56 \%$ & \multirow{10}{*}{34} & 5 & $14.71 \%$ & \multirow{10}{*}{39} & 4 & $10.26 \%$ & \multirow{10}{*}{13,061} & 287 & $2.20 \%$ \\
\hline & Pyrolysis & & 2 & $2.25 \%$ & & 4 & $11.76 \%$ & & 1 & $2.56 \%$ & & 1,582 & $12.11 \%$ \\
\hline & Gasification & & 7 & $7.87 \%$ & & 3 & $8.82 \%$ & & 2 & $5.13 \%$ & & 1,612 & $12.34 \%$ \\
\hline & Torrefaction & & - & $0.00 \%$ & & - & $0.00 \%$ & & - & $0.00 \%$ & & 149 & $1.14 \%$ \\
\hline & Co-firing & & 2 & $2.25 \%$ & & - & $0.00 \%$ & & 1 & $2.56 \%$ & & 190 & $1.45 \%$ \\
\hline & Thermo-chemical & & 1 & $1.12 \%$ & & - & $0.00 \%$ & & - & $0.00 \%$ & & 401 & $3.07 \%$ \\
\hline & Catalysis & & 1 & $1.12 \%$ & & 3 & $8.82 \%$ & & 1 & $2.56 \%$ & & 967 & $7.40 \%$ \\
\hline & Bio-chemicals & & 4 & $4.49 \%$ & & 3 & $8.82 \%$ & & 5 & $12.82 \%$ & & 722 & $5.53 \%$ \\
\hline & Fermentation & & - & $0.00 \%$ & & 2 & $5.88 \%$ & & 7 & $17.95 \%$ & & 1,238 & $9.48 \%$ \\
\hline & Drying & & 20 & $22.47 \%$ & & 12 & $35.29 \%$ & & 17 & $43.59 \%$ & & 3,706 & $28.37 \%$ \\
\hline
\end{tabular}


Supplementary Table 8: Coverage of Bioenergy Research Themes by Different Types of Bioenergy Models - Bioenergy Systems Issues

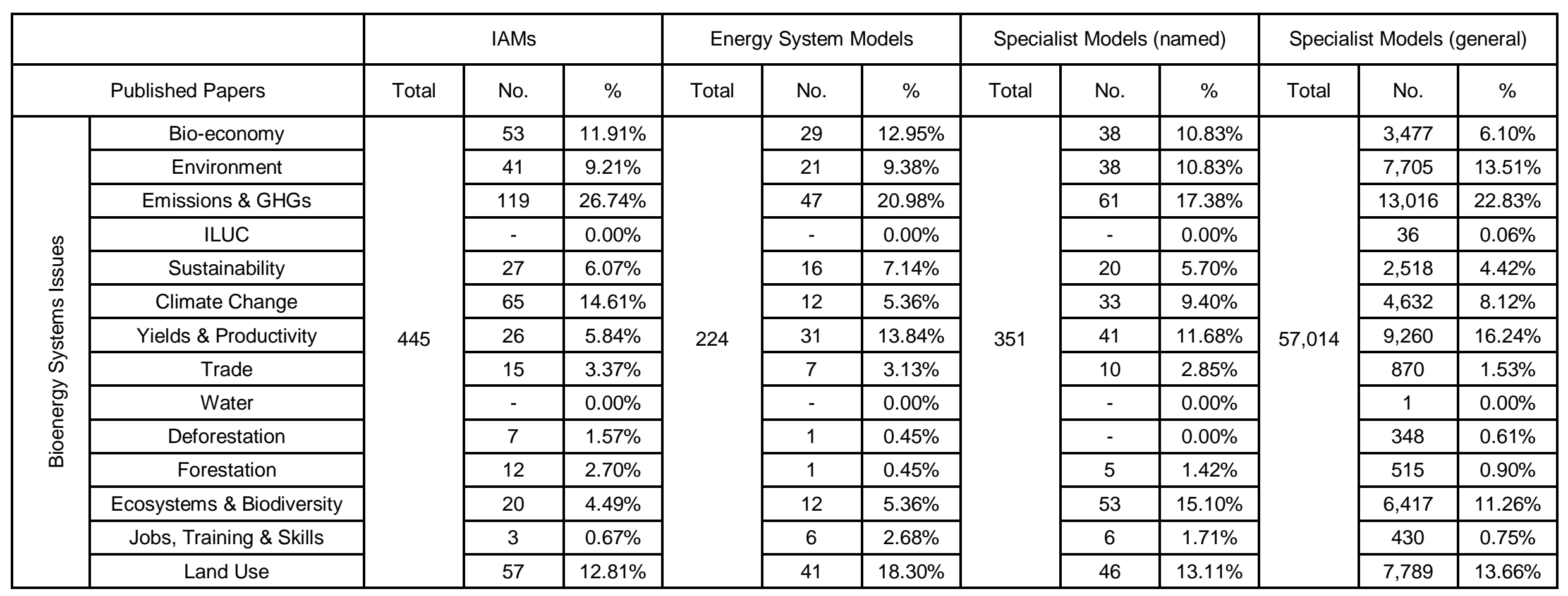


Supplementary Table 9: Coverage of Bioenergy Research Themes by Different Types of Bioenergy Models - Bioenergy Vectors

\begin{tabular}{|c|c|c|c|c|c|c|c|c|c|c|c|c|c|}
\hline & Published Papers & \multicolumn{3}{|c|}{ IAMs } & \multicolumn{3}{|c|}{ Energy System Models } & \multicolumn{3}{|c|}{ Specialist Models (named) } & \multicolumn{3}{|c|}{ Specialist Models (general) } \\
\hline \multirow{7}{*}{ 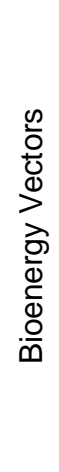 } & BioPower & \multirow{7}{*}{324} & 55 & $16.98 \%$ & \multirow{7}{*}{188} & 26 & $13.83 \%$ & \multirow{7}{*}{222} & 22 & $9.91 \%$ & \multirow{7}{*}{49,575} & 2,726 & $5.50 \%$ \\
\hline & Transport Biofuels & & 48 & $14.81 \%$ & & 19 & $10.11 \%$ & & 11 & $4.95 \%$ & & 4,561 & $9.20 \%$ \\
\hline & Aviation & & 1 & $0.31 \%$ & & - & $0.00 \%$ & & - & $0.00 \%$ & & 32 & $0.06 \%$ \\
\hline & Heavy Goods Haulage & & - & $0.00 \%$ & & - & $0.00 \%$ & & - & $0.00 \%$ & & 5 & $0.01 \%$ \\
\hline & Bio-chemicals & & - & $0.00 \%$ & & 1 & $0.53 \%$ & & 3 & $1.35 \%$ & & 744 & $1.50 \%$ \\
\hline & Bio-Syngas & & 3 & $0.93 \%$ & & - & $0.00 \%$ & & - & $0.00 \%$ & & 528 & $1.07 \%$ \\
\hline & Ecosystem Services & & 5 & $1.54 \%$ & & 2 & $1.06 \%$ & & 5 & $2.25 \%$ & & 669 & $1.35 \%$ \\
\hline
\end{tabular}

